\title{
BARRIERS TO ENTRY AND COMPETITIVE BEHAVIOR: EVIDENCE FROM REFORMS OF CABLE FRANCHISING REGULATIONS*
}

\author{
SutiRTHA BAGCHI ${ }^{\dagger}$ \\ JAGADEESH SIVADASAN ${ }^{*}$
}

\begin{abstract}
Between 2005 and 2008, nineteen of the fifty states of the U.S. reformed the franchising process for cable television, significantly easing entry into local markets. Using a difference-in-differences approach that exploits the staggered introduction of reforms, we find that prices for 'Basic' service declined systematically by about 5.5 to 6.8 per cent following the reforms, but we find no statistically significant effect on average price for the more popular 'Expanded Basic' service. We also find that the reforms led to increased actual entry in reformed states, by about $11.6 \%$ relative to non-reformed states. Our analysis shows that the decline in price for 'Basic' service holds for markets that did not experience actual entry, consistent with limit pricing by incumbents. To control for potential state-level shocks correlated with the reforms, we undertake a sample-split test that finds larger declines in prices for both 'Basic' and 'Expanded Basic' services in local markets which faced a greater threat of entry (because they were close to a prominent second entrant). Our results are consistent with limit pricing models that predict incumbents respond to increased threat of entry, and suggest that the reforms facilitated entry and modestly benefited consumers in reformed states.
\end{abstract}

\section{INTRODUCTION}

WATCHING TV IS THE PREDOMINANT LEISURE ACTIVITY IN THE U.S., accounting for about half of leisure time on average for American adults (BLS [2013]). Cable television plays a very significant role in this activity, with a share of over $60 \%$ of U.S. households in 2010 (Nielsen [2011]). For an industry with such a significant presence in households across the nation, cable television has faced little competition in many local markets, despite federal reforms such as the Cable Act of 1992 and the Telecommunications Act of 1996 that aimed specifically to enhance competition. In particular, based on a 2009 survey, the FCC

\footnotetext{
*We thank the Editor and two anonymous referees for their suggestions, Ying Fan and Jeremy Fox for detailed comments on an earlier draft, Haitao Yin for sharing data on composition of state legislatures, and Ali Yurukoglu for sharing his hand-collected data on cable prices. We also thank (without implicating) seminar participants at the University of Michigan, the Annual International Industrial Organization Conference, 2012, and the Midwest Economic Association Annual Conference, 2011, for comments on an earlier version of the paper. All remaining errors are our own.

†Authors' affiliations: Department of Economics, Villanova University, Villanova, Pennsylvania, U.S.A.

e-mail: sutirtha.bagchi@villanova.edu

$¥$ University of Michigan Ross School of Business, Ann Arbor, Michigan, U.S.A. e-mail: jagadees@umich.edu
} 
documented effective competition (from either satellite TV (DBS) or a second wireline operator) for only $31.65 \%$ of subscribers (FCC [2011], p. 18), implying that $68.35 \%$ of subscribers did not have competitive offerings to choose from.

Policy measures to boost competition in the cable industry continue to be debated at the state and federal levels. In this paper, we examine the impact of one such reform - the deregulation of the franchising process for cable television, which was adopted in nineteen states of the U.S. between 2005 and 2008. Prior to 2005 , in all but four states, prospective entrants to any local market (termed as 'community') had to negotiate with local municipalities on a case-by-case basis. Because the local authorities often imposed significant restrictions on the new entrants, the need to negotiate individually with local municipalities posed a challenge to potential entrants, with the FCC's concluding that the 'local franchising process in many jurisdictions constitutes an unreasonable barrier to entry that impedes...cable competition' (FCC [2006]).

Following deregulation of the franchising process, reformed states allowed cable companies to receive a single state-wide franchise for providing service to communities anywhere within the state. By standardizing the terms and conditions that apply to both existing providers and new entrants into this industry, the reforms effectively liberalized entry by reducing the restrictions typically imposed on new entrants by local city councils (FCC [2006], FCC [2007], Bolema [2008]). The significance of the reforms is reflected in the intense lobbying and legal efforts undertaken by incumbents to delay the reforms and by telecom companies ('Telcos') in support of the reforms. ${ }^{1}$

Although these reforms were the subject of strong debate and lobbying efforts, there has been surprisingly little systematic evaluation of the effect of the reforms, and anecdotal evidence on the effect of the reforms is mixed. ${ }^{2}$ In addition to being of direct policy relevance, studying these reforms provides a unique opportunity to examine the effects of a reduction in barriers to entry on incumbent behavior. As pointed out by Goolsbee and Syverson [2008], the effect of an increased threat of entry has been a topic of interest in the theoretical literature, but has been surprisingly less investigated empirically, as it is difficult to find instances where the threat of entry went up without necessarily inducing actual entry. More broadly, the reforms provide a setting to study the effect of competition on firm behavior: changes in regulatory barriers to entry help overcome the difficult challenge of finding exogenous sources of variation in the competitive environment (Holmes and Schmitz [2010]).

Because deregulation was introduced across the nineteen states in a staggered manner, we are able to adopt a standard difference-in-differences (DID) approach exploiting variation in the timing of introduction to control for common shocks

\footnotetext{
${ }^{1}$ For anecdotal evidence on the lobbying efforts see news articles by e.g., Reardon [2005a], Haugsted [2006], Sura [2006] and Sher [2008].

2 Articles about specific states suggesting consumers benefited include Spiwak [2006] (Texas), Schneider [2007] (Wisconsin) and Rogers [2008] (Michigan), while Kreucher [2008] (Michigan) and Barrett [2008] (Wisconsin) argue otherwise.
} 
(Angrist and Pischke [2009], Ch 5). Using a rich micro data set which includes data on prices of cable television in every local community across the United States over a seven-year period from 2004 to 2010, we examine whether the price of subscribing to the two primary service tiers - 'Basic' and 'Expanded Basic' - declined in response to these reforms. ${ }^{3}$ Complementing this dataset with hand-collected data on entry by the two major Telcos, Verizon and AT\&T, we also examine how entry by cable operators and Telcos was affected by the reforms.

We find that prices for 'Basic' service are lower by about 5.5 to $6.8 \%$ in states which have reformed their franchising process for cable television. We find no effect on prices of the more popular 'Expanded Basic' service tier. We confirm that the DID effects were not impacted by pre-existing trends - the trends in prices for both 'Basic' and 'Expanded Basic' service in the reformed states were not different from that in the non-reformed states.

While the Warren's Television and Cable Factbook database has been extensively used in prior studies (e.g., Rubinovitz [1993]; Goolsbee and Petrin [2004]; DellaVigna and Kaplan [2007]; Seamans [2013]), recently researchers have documented issues with the quality of longitudinal data in this dataset (e.g. Crawford and Yurukoglu [2012]; Martin and Yurukoglu [2016]). In particular, they find that data do not appear to be updated regularly for a significant number of cable systems. While we do not expect the measurement issue to systematically bias our results against the null of a zero effect for reforms, we undertake three alternative tests to check the robustness of our results to these concerns about the quality of longitudinal data. Specifically, we test robustness to including only communities with at least one price change, to using only sample period means pre and post-reform, and finally to including cable system level fixed effects. We find the baseline results robust, with the decline in price of 'Basic' service stronger in one of the tests, and the null effect for 'Expanded Basic' remaining unchanged (both in terms of magnitude and statistical significance).

We also find the baseline results robust to a range of additional robustness checks. In particular, we find the results robust to including additional controls for quality of channels offered (in addition to the control for number of channels), including amortized costs of installation in the price, examining long differences, restricting analysis to a balanced panel of communities, using alternative fixed effects, including only principal communities, excluding some sub-sets of states, and distinguishing multi-system operators from smaller firms. As a falsification test, we check and find no effects using residential, commercial, and industrial electricity prices. Finally, we find that quantity (measured as number

\footnotetext{
3 'Basic' cable service, also referred to as the basic service tier ('BST'), is the minimum level of cable television service that must be taken by all cable television subscribers. The content of basic cable service varies among cable systems but, pursuant to the Communications Act, must include all local television signals and public, educational, and governmental access channels and, at the discretion of the cable operator, may include other video services. 'Expanded Basic' cable service, offers additional video channels on one or more service tiers (FCC [2009], p. 12).
} 
of subscribers) went up in response to the price decline, though the estimated effects are noisy.

We then examine entry, and find evidence of significant additional entry in reformed states, particularly by Telcos. While raw summary statistics suggest about $13.3 \%$ more communities in reformed states experienced entry, controlling for demographic and market characteristics in a linear propensity model, we find a DID excess entry rate between $7.95 \%$ and $13.8 \%$ in the reformed states.

Our findings carry implications for related theoretical literature. As we discuss in Section III, the theoretical predictions about the effect of a reduction in costs of entry vary across models (as discussed in detail in Sutton [1991]). For example, in a model where potential entrants expect Bertrand competition in the second stage after entry, they would not enter and the incumbent would not change behavior, as long as sunk costs of entry are greater than zero (which is very likely the case in our context, as entry requires considerable upfront capital investment), even if the reforms reduce some costs associated with negotiating local franchises. In other models (e.g., a model where the post-entry behavior is expected to be Cournot competition) there is indeed entry, and post-entry prices are lower than under monopoly. The baseline results on price, and more importantly on entry, suggest evidence against the Bertrand model and potentially in favor of the other models.

In this context, an interesting question is whether we should expect any price declines without actual entry occurring. The models in Sutton [1991], do not explicitly address this question, but do predict declines post-entry. Milgrom and Robert [1982a] show that in a world with perfect information, cutting prices prior to entry does not deter entry, and hence such 'limit pricing' behavior would not be a rational equilibrium. However, in a world with asymmetric information (Milgrom and Roberts [1982b]) or with switching costs (Klemperer [1987]), incumbents may lower prices before entry to signal lower costs or to lock up consumers; thus in these models limit pricing can be a rational strategy to deter entry.

We examine whether there is evidence for ex ante price declines, by excluding communities which experienced actual entry from the sample. We find that indeed there is evidence for incumbents' cutting price in response to just the enhanced threat of entry: communities without entry have a greater price decline of $6.57 \%$ for 'Basic' service, in reformed states relative to non-reformed states. ${ }^{4}$

Building on this finding that the increased threat of entry led to price declines, we devise a sample-split (triple difference) test that controls for potential statelevel correlated shocks. In particular, we examine communities in counties where

\footnotetext{
${ }^{4}$ Interestingly, comparing communities where there was actual entry, we see no significant differences between reformed and non-reformed states. This is unsurprising as most models do not predict differences between reformed and non-reformed states conditional on actual entry. In fact this result is reassuring, as it suggests that omitted variables were not driving general price declines in reformed states.
} 
a major overbuilder is present. ${ }^{5}$ Incumbents here are likely to face a relatively greater threat of entry, as cable overbuilders are more inclined to enter into neighboring communities (RCN 2005 Annual Report, Seamans [2013]). We find that there is indeed a greater DID decline in price in communities close to a major overbuilder; this decline is about $10.6 \%$ and statistically significant for 'Basic' service, and equally large (10.2\%) but statistically less significant for 'Expanded Basic' service. Interestingly, consistent with the observed price cuts, we find very large and statistically significant increases in number of subscribers for both 'Basic' and 'Expanded Basic' services in communities close to the major overbuilder. As long as potential omitted shocks, due to unobserved demand (e.g., due to differential entry by Satellite TV) or cost shifters (e.g., due to local cost inflation not captured by local income or wages included in baseline controls) are similar across locations within a state, this sample-split result suggests that reforms did indeed cause changes in incumbent behavior, consistent with the models that predict ex ante price responses (such as Milgrom and Roberts [1982b] or Klemperer [1987]).

While our main focus is on the effect of these reforms on prices of various tiers of cable service, there are a number of other outcomes that could be potentially impacted by an increase in competition. In particular, the quality of service, as also the pricing of broadband (internet) service could be impacted; subject to limitations on availability of data, we briefly examine these outcomes as well. Consistent with the results in Chu [2010], who finds that the quality of cable service (measured as number of channels) typically improved in response to satellite entry, we find some evidence of an increase in quality of service for the 'Basic' tier following the reforms. Thus, incumbent firms appear to have responded to an increased threat of entry on the service quality margin (and the observed price declines are not offset or explained by a reduction in the quality of service). We also find some evidence of a decline in the price of internet service, again with stronger effects in markets with a higher threat of entry.

Our study contributes to the small literature discussing the effect of cable franchising deregulation (Spiwak [2006], Schneider [2007], Bohanon and Hicks [2010]). To the best of our knowledge, our study is the first to systematically examine the effects of cable franchise deregulation on prices, and entry using comprehensive national microdata, and hence the first to document systematic declines in prices and increased entry in reformed states. The FCC in its periodic cable price reports examines differences in prices across communities, including comparison between communities with and without a second cable operator. In its 2009 report on cable industry prices, it finds that average price of the 'Basic' tier is about 10.23 (10.91) per cent lower in 2009 (2008) in communities where

\footnotetext{
${ }^{5}$ As discussed in FCC ([2009], p. 15, footnote 97), the term 'overbuild' describes the situation in which a second cable operator enters a local market in direct competition with an incumbent cable operator. In these markets, the second operator, or 'overbuilder,' lays wires in the same area as the incumbent, 'overbuilding' the incumbent's plant, thereby giving consumers a choice between cable service providers.
} 
there is a second cable operator ('overbuild') (Table I, FCC [2011]). Thus our finding of a range of 5.5 to 6.8 per cent decline in prices suggests an effect in the range of 50 to 66 per cent of the effect of actual overbuild competition. ${ }^{6}$

Because we find ex ante price responses by incumbents to the increased threat of entry, this study relates to the empirical literature on ex ante price reductions or limit pricing. Although a number of studies have examined ex post responses by incumbents to entry (Yamawaki [2002], Simon [2005], McCann and Vroom [2010]), relatively few have examined ex ante responses. In an important contribution, Goolsbee and Syverson [2008] find that incumbents respond to the threat of entry by a low-cost competitor (Southwest) by preemptively reducing prices. In work related to ours, Seamans [2013] examines limit pricing behavior in cable TV markets. Using a novel measure that captures variation in asymmetric information between incumbents and new entrants across markets, he finds that limit pricing behavior is indeed more strongly prevalent in markets with a greater degree of asymmetric information, consistent with the model in Milgrom and Roberts [1982b]. Our work differs in that we focus on inter-temporal variations in barriers to entry introduced by reform of local franchising regulations. In addition to testing for the presence of limit pricing, our objective is also to undertake an evaluation of this important policy reform.

The cable industry provides an interesting setting for empirical work because there are numerous geographically separated markets. Our work relates to the broader literature in Industrial Organization that has exploited this setting to examine various aspects of the cable market including the effect of vertical integration between programming and distribution (Chipty [2001]), welfare effects of bundling (Crawford [2008] and Crawford and Yurukoglu [2012]), and welfare effects of new products (Goolsbee and Petrin [2004]).

The paper proceeds in nine sections. Section II provides background on the industry, regulations, and the state-level reforms that are the focus of this study. Section III lays out the theoretical underpinnings for our empirical analysis, while Section IV introduces the data. Section V presents our analysis of the effect of reforms on prices and provides several robustness checks on our main set of results. Section VI examines actual entry following the enactment of these reforms, and examines whether incumbents responded to increased threat of entry. Section VII presents the sample-split test examining communities adjacent to major overbuilders. Section VIII presents a number of extensions examining the effect of the reforms on the quality of service, on the price of internet service, and results from a two-step matching procedure that controls for the potential endogeneity of these reforms. We discuss results and conclude in Section IX.

\footnotetext{
${ }^{6}$ The findings for the effect of actual overbuild competition on 'Expanded Basic' tier is a bit more nuanced in the 2009 report (FCC [2011]). While the average price of service is only $1.0(2.39)$ per cent lower, consistent with Chu's [2010] findings for the effect of Satellite entry on number of channels offered, the 2009 report finds a greater number of channels being offered in the 'Expanded Basic' tier in communities with overbuild competition, so that per channel price is 11.11 (14.49) per cent lower in communities with actual overbuild in 2009 (2008).
} 


\section{INDUSTRY BACKGROUND, REGULATORY FRAMEWORK AND REFORMS}

\section{II(i). Industry Background}

For studying the effect of changes in entry barriers, an attractive feature of cable TV markets is their localized nature, which allows for considerable variation in the competitive settings across geographic markets. These local markets are defined by the 'franchise' boundary of the incumbent system; typically the boundary is the geographical boundary of the city in which the incumbent system is based. This effectively segments the U.S. into thousands of non-overlapping geographic markets.

Historically, a single incumbent cable TV system served each local market. In their 2009 annual report, the Federal Communications Commission notes that: 'Relatively few consumers have a second wireline alternative, such as an overbuild cable system' (FCC [2009], p. 5). An earlier FCC Report on Cable Industry Prices (FCC [2005]) found that cable television service was provided in 32,510 'non-competitive' communities while there were only approximately 400 communities with competitive wire line 'overbuilds' (i.e., with more than one operator in the market) (Braunstein [2008]).

Although in theory competition from Direct Broadcast Satellite (DBS) could have limited the amount of pricing power enjoyed by cable TV incumbents, this appears not to have been borne out in practice for the period of our study. An assessment by the FCC in 2009 noted that '.. in the large number of communities in which there has been a finding that the statutory test for effective competition has been met due to the presence of DBS service, competition does not appear to be restraining price as it does in the small number of communities with a second cable operator. ${ }^{17,8}$

Traditionally, one reason proposed for why most markets remain monopolies (in terms of wired cable service) is the potentially significant economies of scale in providing cable service and the large investments required for laying coaxial cable to the homes of consumers. However, Owen and Greenhalgh [1986] argue that economies of scale are not so large as to rule out the possibility that competition, either direct or potential, can serve as a significant disciplinary force in the marketplace. More recently, Kelly and Ying [2003] find that 'average cost savings with respect to a monopoly were fairly small, ranging from $1.37 \%$ with a $10 \%$ market overlap to $5.05 \%$ with a complete overbuild' (Kelly and Ying, [2003], p. 962). Another significant factor contributing to the persistence of local monopolies has been local 'franchising' regulations (FCC [2006], FCC [2009]),

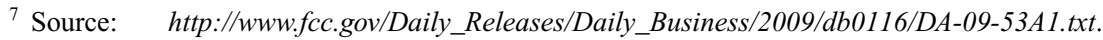
Accessed on 1 December, 2012

${ }^{8}$ Because barriers to DBS entry were related to geographical factors (Goolsbee and Petrin [2004]), we do not expect entry rates to be correlated with reforms in a way that would bias our results. Nevertheless in Section VII, below, we discuss a sample-split (triple difference) approach that could control for shocks correlated with the reforms such as higher DBS entry into reformed states.
} 
which have acted as a significant barrier to market entry. We discuss these local franchising regulations in the next section.

\section{II(ii). Franchising Regulation of Cable Service Providers}

Cable companies have been traditionally regulated at the local level. To obtain permission from local government authorities to operate in a market, firms are required to agree to a number of terms as part of a 'franchise' agreement. Local governments use these agreements to achieve multiple goals including raising revenue, providing access to cable TV equitably in the community, and minimizing disruptions from laying of cable. In particular, some of the key terms relate to:

- Franchise fees: Franchise fees to be paid annually typically amount to 5\% of the revenue received by cable companies. These can be important sources of revenue for local governments. ${ }^{9}$

- Build-out provisions: The desire of local governments to provide access to consumers everywhere within their service jurisdiction generally leads them to prescribe build-out requirements where entrants are obligated under the franchise agreement to cover the entire service area within a prescribed span of time.

- Public, Education, and Government (PEG) channels to be carried on the service.

- Service networks to government and educational buildings (I-Net).

- Local agency control over public rights-of-way permits: These terms aim to minimize disruptions that would result from uncoordinated digging up of roads and walkways by cable companies.

- Consumer protection through customer service standards and enforcement.

Per the FCC (FCC [2006], FCC [2009]), the local franchising process imposes significant barriers for potential wireline entrants. In his study, Hazlett [2007] concludes that the local permitting process delays competitive entry, and depending on the nature of the administrative process and the terms and conditions imposed on the potential entrant, franchising may deter entry altogether.

Federal policy makers sought to outlaw anti-competitive build-out requirements and prevent discriminatory pricing that limit competition, through the Telecommunications Act of 1996. However, because municipal franchising agents were granted immunity from damage awards, there is no effective remedy if regulators impose unreasonable build-out requirements, or fail to enforce

\footnotetext{
${ }^{9}$ A government committee report (Joint Study Committee [1998]) in Georgia documented that for the 525 governmental units studied, cable franchise fees represented an average of $6.66 \%$ of total tax revenues. A recent estimate for aggregate franchise fees paid by cable operators is $\$ 3.2$ billion per year, per the Cable \& Telecommunications Association. (http://www.ncta.com/Statistics.aspx Accessed on 10 December, 2012.)
} 
uniform pricing rules. An FCC [2007] report found that the franchise process was being manipulated so that 'new entrants eager to provide video service are often delayed, and in some cases derailed, by the unreasonable demands made by local franchising authorities.' This report reiterated the findings in an earlier FCC [2006] order, where the Commission concluded that: 'the operation of the local franchising process in many jurisdictions constituted an unreasonable barrier to entry...' The FCC [2006] order discusses several ways by which local franchising authorities were unreasonably refusing to award competitive franchises. These include drawn-out local negotiations with no time limits; unreasonable build-out requirements; unreasonable requests for 'in-kind' payments that attempt to subvert the five per cent cap on franchise fees; and unreasonable demands with respect to public, educational and government access (or 'PEG') channels.

\section{II(iii). Reforms of Cable Franchising Regulation}

Given the reality of limited competition in the cable industry, there have been a number of attempts at both the state and federal level to enhance competition (Spurgin [2008]). ${ }^{10}$ These have often taken the form of limiting local government's ability to regulate competitive cable operators and allow for the possibility of issuing statewide or nationwide cable franchises to companies interested in providing cable service, whether they be cable or telecom companies.

Although no federal action for nationwide franchising has been taken to date, twenty-three states have reformed their franchising process to allow for statewide franchises. Such laws pre-empt the need for new entrants to negotiate individual franchise agreements with local municipal authorities, and give them the authorization to launch services anywhere in the state following approval of the state-wide franchise application.

Table I shows the status of franchise reform in all fifty states, along with the year of passage for all states that have reformed their franchising process. Four states, Alaska, Hawaii, Rhode Island and Vermont, had state franchising laws in place prior to 2005; nineteen states passed similar laws between 2005 and 2008.

For the states that have passed state-wide cable television/video franchise laws, Spurgin [2008] provides a general comparison of key provisions (see Table A1 in the Online Appendix) including variations in the franchise fees, requirements on provision of Public, Educational and Government Access (PEG) channels, controls on Right of Way, and build-out requirements by state. We supplemented Spurgin [2008] by a review of the legislative bills; based on our review, we reclassified Virginia as 'not reformed,' as the legislation for the state did not include a provision for a single state-wide franchise. Also, we confirmed passage of the law for Louisiana, where the legislation was pending per Spurgin [2008].

${ }^{10}$ This section draws from Spurgin [2008]. 
TABLE I

Status of Cable Franchise Reform Legislation in All Fifty States

4 States with laws prior to 2005 :

Alaska, Hawaii, Rhode Island, and Vermont

19 States that enacted laws in 2005, 2006, 2007, or 2008:

2005: Texas

2006: Indiana, Kansas, Michigan, New Jersey, and North Carolina

2007: California, Connecticut, Florida, Georgia, Illinois, Iowa, Missouri, Nevada, Ohio, South Carolina, and Wisconsin

2008: Louisiana and Tennessee

27 States that have not enacted laws:

Alabama, Arizona, Arkansas, Colorado, Delaware, Idaho, Kentucky, Maine, Maryland,

Massachusetts, Minnesota, Mississippi, Montana, Nebraska, New Hampshire, New

Mexico, New York, North Dakota, Oklahoma, Oregon, Pennsylvania, South Dakota,

Utah, Virginia, Washington, West Virginia, and Wyoming

Source: 'State Video Franchise Law: State of Art or State of War?' by Jay T. Spurgin [2008] supplemented by authors' research.

A number of states set up separate commissions specifically charged with overseeing the new state franchises. Franchise fees for new service providers with a state-issued franchise are set by most states to be equal to incumbent fees, with a maximum amount typically being five per cent of gross revenues. Buildout requirements under state franchise laws are generally less stringent than under local franchise agreements. Very few bills to date have included build-out provisions, and those that do are heavily qualified. ${ }^{11}$

Given that the critical provisions (relating to granting a state-wide franchise to the applicant, equating of franchisee fees between entrants and incumbents, and relaxation of build-out requirements) are similar across the different reformed states, in our analysis we treat the reforms as a dichotomous variable. As noted before (in footnote 1), incumbent cable companies lobbied strongly against franchising reforms, while telecom companies, specifically Verizon and AT\&T, worked to support these legislations.

As discussed earlier, there is little work systematically examining the effect of the reforms on prices and entry across all reformed states. Bohanon and Hicks [2010] examine the effect of franchising reforms on number of broadband connections using FCC data, and they find an increase in broadband subscriptions following the reforms. Anecdotal evidence on the effect of reforms in particular states has been mixed with some reports of reduced prices after entry (e.g., Spiwak [2006] (Texas), Schneider [2007] (Wisconsin) and Rogers [2008] (Michigan)), and other reports of no decline in prices (e.g., Kreucher [2008] (Michigan) and Barrett [2008] (Wisconsin)).

\footnotetext{
${ }^{11}$ Most state laws that provide for a state-wide franchising authority allow existing local franchise agreements to remain in effect until a new service provider with a state-issued franchise begins offering service in a community. Many states allowing existing franchises the option to terminate the local franchise and replace it with a state franchise; some restrict this option to when wireline competition is present.
} 


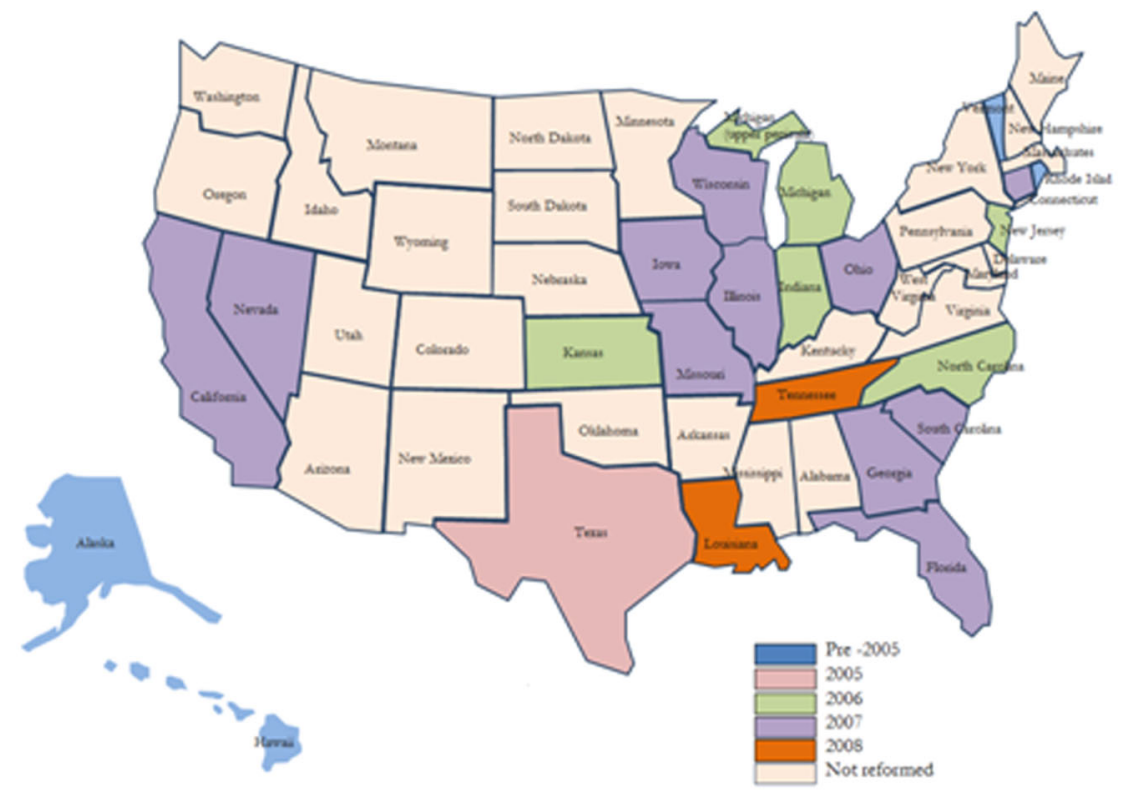

Figure 1

Progression of Reforms across the 50 States

Notes: Based on Spurgin [2008]. We recoded Virginia (which had been listed in the report as reformed) as not reformed because our research shows that the state did not pass legislation allowing for a state-wide franchise. Also, we confirmed passage of the law for Louisiana, where the legislation was pending per Spurgin [2008].

\section{THEORETICAL BACKGROUND}

We view the enactment of reform that allows for the award of a single state-wide franchise as reducing the barriers to entry in the market for cable TV services, by reducing the exogenous, sunk costs associated with entering each local market.

In a large class of models, reduced (sunk) entry costs could lead to more entry in equilibrium which then puts downward pressure due to post-entry competition (e.g., in the Cournot or Monopoly model in Chapter 2 of Sutton [1991]). However, as Sutton [1991] discusses in Chapter 2, this result hinges on assumptions about the nature of price competition in the post-entry stage. $\mathrm{He}$ shows for example that assuming homogeneous products and Bertrand competition in the second stage, a reduction in entry costs does not necessarily attract new entry, as entrants anticipate price to equal marginal cost post-entry in the second stage, and this completely deters entry. In fact in the Bertrand model, changes in exogenous sunk entry costs have no effect on the pricing behavior 
of the incumbent, as they charge the monopoly price as long as entry costs are non-zero. ${ }^{12}$

In contrast to the models in Sutton [1991], in the presence of asymmetric information about incumbent's costs (Milgrom and Roberts [1982b]) or if customers face switching costs (Klemperer [1987]), the theoretical literature suggests incumbents may change pricing behavior in response to an increased threat of entry, even before actual entry occurs, as a means to try and deter entry. ${ }^{13}$ In Milgrom and Roberts [1982b], incumbents may lower prices to signal lower costs; because lowering prices is costly, it constitutes a credible signal to potential entrants. It should be noted that, as Milgrom and Roberts [1982a] show, cutting prices prior to actual entry is not a rational strategy to deter entry (or drive out rivals) in a world of complete information (and no switching costs). Potential entrants would realize that prices are being held artificially low in order to ward off entry but then once entry does take place, it is sub-game perfect for the incumbent to accommodate rather than to predate. In other words, as long as the established firm's pre-entry price does not affect post-entry demand or cost (and hence profit), limit pricing would not influence the potential entrant's decision to compete in the market. Thus the asymmetric information assumption in Milgrom and Roberts [1982b] is crucial to get rational ex ante price cuts to deter entry. Asymmetric information could be relevant in our context due to cross-industry differences between Telco entrants and cable incumbents, or participation in industry R\&D consortia (as discussed in Seamans [2013]). ${ }^{14}$

Klemperer [1987] provides another justification for ex ante price cuts - in his model lower prices help to 'lock in' more consumers, who are harder for the entrant to attract because of switching costs. In our context, there may be switching costs for several reasons. One, it was not unusual for companies to offer one and even two-year contracts, with an early termination fee. Two, even without early termination, switching could involve upfront installation fees. Also, lack of experience with the new service provider may yield a psychic switching cost due to potential concerns about service quality and customer support. In both Milgrom and Roberts [1982b] and Klemperer [1987], reducing prices is costly for the incumbent and so it follows that incumbents may be more likely to reduce prices the stronger the threat of entry.

\footnotetext{
12 Also with product-differentiation, different models yield different predictions about the equilibrium number of firms in the market after reduction in entry costs. In the Hopenhayn [1992] class of industry equilibrium models, the effect of reduced sunk costs of entry on the mass of survivors is ambiguous (Balasubramanian and Sivadasan [2009]), but the cutoff productivity level increases and consequently, the equilibrium rate of entry (and exit) goes up.

${ }^{13}$ The idea of ex ante limit pricing goes back to Bain [1956], who suggested that there may be a positive relationship between the initial price and the degree of entry - an incumbent firm may select lower than the profit maximizing price in order to deter entry by competitors.

14 Seamans [2013] argues that variation in membership in CableLabs, an industry R\&D consortium restricted to cable companies, is an important source of asymmetric information, and exploits that in his study.
} 
To summarize, the effect of reduction in entry barriers on actual entry as well as pricing behavior of the incumbent is theoretically ambiguous with at least one model (Bertrand competition model in Sutton [1991]) suggesting possibility of no effect on prices or actual entry. Other models suggest actual entry and consequent decline in prices (Cournot competition model in Sutton [1991]) while others predict price declines even without actual entry (Milgrom and Roberts [1982b], or Klemperer [1987]). Given the varying predictions across different models, the cable reforms provide an interesting context in which to empirically investigate the effects of a reduction in entry barriers, specifically: (i) whether prices were affected, (ii) whether actual entry occurred, and (iii) whether there was evidence for ex ante price reductions (as predicted by Milgrom and Roberts [1982b] or Klemperer [1987]).

\section{DATA AND SUMMARY STATISTICS}

The primary source of data on cable television service offerings comes from seven years (2004-2010) of the Warren Publishing's Television and Cable Factbook. The Factbook data is the main source of cable TV system level characteristics used in most empirical studies of the industry (e.g. Rubinovitz [1993]; Goolsbee and Petrin [2004]; DellaVigna and Kaplan [2007]; Seamans [2013]). ${ }^{15}$ This rich data set includes information on monthly prices and installation fees, the number of consumers subscribing to the various tiers of service, and a listing of the specific channels that are available on each tier of service for each individual cable system. It also classifies each system as either 'Operating' or 'Overbuild' where the latter term refers to a competing cable operator building a cable network system in an area already serviced by an existing cable operator. Finally, it also provides us the names of the communities which are served by each cable system. ${ }^{16}$ While the Warren's Factbook database has been used extensively in the literature, there are some concerns about the quality of longitudinal data in the dataset; we discuss this concern and undertake robustness checks to check potential bias from related measurement error in Section V(iv) below.

In addition to data regarding the service offerings, we obtain controls for demographic variables that might affect either the demand for cable television service

\footnotetext{
${ }^{15}$ It is also used extensively by the FCC. Justifying the use of data from this source, an FCC report says: 'Warren collects its data directly from cable television operators or individual cable systems to create a large database of cable industry information. Warren states that it is the only research entity that directly surveys every cable system at least once every year, providing the most complete source of cable data. In fact, the cable systems represented in Warren's database serve $96 \%$ of all subscribers nationwide.' (FCC [2009], p. 198).

${ }^{16}$ For example, the cable system in Kalamazoo, Michigan, serves not just the city of Kalamazoo but also towns in the adjoining area such as Alamo Township, Pavilion Township and Comstock Township. The Warren's data includes the names of the principal community (in this case, Kalamazoo) as also the names of adjoining communities served by the cable system (in this case, Alamo Township, Pavilion Township, and Comstock Township).
} 
TABLE II

Summary Statistics - Number of Communities

\begin{tabular}{lcccccccc}
\hline Reform Status & 2004 & 2005 & 2006 & 2007 & 2008 & 2009 & 2010 & Total \\
\hline No reform & 16,320 & 16,191 & 15,622 & 15,077 & 14,172 & 14,221 & 14,012 & 105,615 \\
Reform before 2005 & 512 & 489 & 487 & 470 & 464 & 463 & 466 & 3,351 \\
Reform between 2005 -2008 & 18,805 & 18,391 & 17,818 & 17,379 & 15,981 & 16,018 & 15,723 & 120,115 \\
Total & 35,637 & 35,071 & 33,927 & 32,926 & 30,617 & 30,702 & 30,201 & 229,081 \\
\hline
\end{tabular}

Notes: The lowest level of disaggregation at which data are available from the Warren's TV Factbook (2004-2010) is the individual community. Generally the boundaries of a cable community correspond to that of a municipality, though there may be multiple cable communities within a single municipality and vice versa. The status of reforms by state is summarized in Table $\mathrm{I}$.

or the cost of providing cable television service or the likelihood of market entry by a competing service provider. We draw on Savage and Wirth [2005] to select relevant control variables; in particular, the demographic controls include per capita income (and its square), population density (and its square), local wage in the 'Information' sector (NAICS code: 51), age profile of the population, and growth in number of housing units. Data on these demographic variables is available at the county level. Additional information regarding data sources is provided in the online Data Appendix.

Tables II and III present summary statistics. Table II gives a snapshot of the number of communities served for each year splitting the sample into the three different categories based on whether the state enacted franchising reforms, and when those reforms were enacted. Generally the boundaries of a cable community correspond to that of a municipality, though there may be multiple cable communities within a single municipality and vice versa. As Table II indicates, there are approximately 30,000 cable communities in the U.S. each year. ${ }^{17}$

Summary statistics at a similar level of disaggregation on price of 'Basic' and 'Expanded Basic' tiers of service are presented in Table III. As the fourth row of Table III suggests, the average price for 'Basic' and 'Expanded Basic' services stand at $\$ 18.98$ and $\$ 42.02 /$ month for the entire sample period, when averaged across all states. ${ }^{18}$ Also, a simple difference in means shows that the increase in average price for 'Basic' service was $8 \%$ lower in the states that reformed between 2005 and 2008; these states move from an average price 46 cents above, to an average price 84 cents below, that for the non-reformed states. The average price for 'Expanded Basic' service moves in tandem in both the states that underwent reform between 2005 and 2008 and the non-reformed states. These aggregate

17 The number of communities in the Warren's data change from year to year, with a broad trend of decline in the number of communities. Warren's informed us that this was due to consolidation of communities. As part of our robustness checks (in Section V(v)), we verify that baseline results hold for a balanced panel sub-sample of communities present throughout the seven-year sample period.

${ }^{18}$ Following a discussion with the data provider, we define the price of 'Expanded Basic' as the sum of 'Expanded Basic' service (only) provided in the Warren's pay tier file with the monthly price for 'Basic' service (only) provided in the Warren's general information file. This is because 'Expanded Basic' access requires purchase of the 'Basic' tier as well. 
TABLE III

Summary Statistics on Monthly Price of 'Basic' and 'Expanded Basic' Service

\begin{tabular}{|c|c|c|c|c|c|c|c|c|}
\hline \multirow[b]{2}{*}{ Reform Status } & \multicolumn{4}{|c|}{ 'Basic' service } & \multicolumn{4}{|c|}{ 'Expanded Basic' service } \\
\hline & 2004 & 2010 & $\begin{array}{c}\text { Average } \\
\text { across the } \\
\text { sample }\end{array}$ & $\begin{array}{c}\% \text { change } \\
\text { between } \\
2004-2010\end{array}$ & 2004 & 2010 & $\begin{array}{c}\text { Average } \\
\text { across the } \\
\text { sample }\end{array}$ & $\begin{array}{c}\% \text { change } \\
\text { between } \\
2004-2010\end{array}$ \\
\hline No Reform & $\$ 17.77$ & $\$ 20.35$ & $\$ 19.11$ & $15 \%$ & $\$ 35.96$ & $\$ 46.85$ & $\$ 41.75$ & $30 \%$ \\
\hline Reform before 2005 & $\$ 17.05$ & $\$ 22.94$ & $\$ 19.39$ & $35 \%$ & $\$ 39.80$ & $\$ 52.79$ & $\$ 46.21$ & $33 \%$ \\
\hline \multicolumn{9}{|c|}{ Reform between } \\
\hline $2005-2008$ & $\$ 18.23$ & $\$ 19.51$ & $\$ 18.85$ & $7 \%$ & $\$ 36.31$ & $\$ 47.20$ & $\$ 42.11$ & $30 \%$ \\
\hline Overall & $\$ 18.00$ & $\$ 19.95$ & $\$ 18.98$ & - & $\$ 36.23$ & $\$ 47.11$ & $\$ 42.02$ & - \\
\hline \multicolumn{4}{|c|}{$\begin{array}{l}\text { Change in reformed states relative } \\
\text { to non-reformed states }\end{array}$} & $\begin{array}{l}=7 \%-15 \% \\
=-8 \%\end{array}$ & & & & $\begin{array}{l}=30 \%-30 \% \\
=0 \%\end{array}$ \\
\hline
\end{tabular}

Notes: Data on cable prices are taken from successive issues of Warren's TV Factbook (2004-2010). Price data are available at the level of each individual community. Generally the boundaries of a cable community correspond to that of a municipality, though there may be multiple cable communities within a single municipality and vice versa. There are approximately 30,000 cable communities in the U.S. 'Basic' service is the level of cable television service that must be taken by all cable television subscribers. The content of basic cable service varies among cable systems but, pursuant to the Communications Act, must include all local television signals and public, educational, and governmental access channels and, at the discretion of the cable operator, may include other video services. 'Expanded Basic' service offers additional video channels on one or more service tiers and includes most of the better-known national cable television networks. The price data provided in this table exclude all installation charges and any charges associated with equipment rental and reflect the monthly subscription charges for an individual consumer. The status of reforms by state is summarized in Table I.

differences in means presage the results we find with more careful regression estimates below.

To examine entry by Telcos, we also hand collected data on locations served by Verizon and AT\&T; this data is described in more detail in Section VI below.

\section{EFFECT OF FRANCHISING REFORMS ON PRICES}

\section{V(i). Empirical Methodology}

The staggered introduction of the reforms across different states allows us to adopt a difference-in-differences approach to estimating the effect of the franchising deregulation. As is standard, we compare the difference in outcomes after and before the intervention for communities affected by the deregulation (the 'treated' group) to the same difference for unaffected communities (the 'control' group) (Bertrand, Duflo and Mullainathan [2004]). We look at the longest period possible from 2004 through 2010, based on availability of data. However, this period is also convenient for us since 2004 corresponds to a date when none of the states, barring four (Alaska, Hawaii, Rhode Island and Vermont) had passed such state-wide legislation and by end-2008, an additional nineteen states had reformed their franchising process giving us at least two years after the enactment of reform to study its effects.

To make an apples-to-apples comparison across different tiers of service (and as is standard, e.g., in FCC reports on the industry), we look at two tiers of 
service individually - the first tier, 'Basic' and the second tier, 'Expanded Basic' - prices for which are reported separately in the Warren's data. Subscribers must purchase 'Basic' service in order to subscribe to 'Expanded Basic' service or to any other tier, or to buy premium programming such as HBO. To be clear, we define price of 'Expanded Basic' as the total price charged to consumers who subscribe to 'Expanded Basic' service, so this incorporates the price for the included 'Basic' tier as well. In our data about 77 per cent of cable subscribers take both 'Basic' and 'Expanded Basic' services; the remaining 23 per cent take 'Basic' service only. Because these two tiers of service make up well over twothirds of the revenue derived from all tiers of TV programming (FCC [2006] p. 19 , FCC [2009] p. 23), we focus on just these tiers for our analysis.

We use the following standard difference-in-differences specification (see, e.g., Angrist and Pischke [2009], Chapter 5), allowing for a different effect in the year of the reform:

$$
p_{i j s t}=\alpha+\beta_{1} \cdot R_{s t}^{0}+\beta_{2} \cdot R_{s t}+\boldsymbol{\beta}_{3} \cdot \mathbf{X}_{\mathbf{i t}}+\boldsymbol{\beta}_{4} \cdot \mathbf{Y}_{\mathbf{j t}}+f_{s}+f_{t}+\varepsilon_{i j s t}
$$

where $p_{i j s t}$ is the log of price for community $i$ in state $s$ at time $t$ for the service offered by company $j$ for a particular service tier. Price varies by service tier and is logged, following other work on pricing (e.g., Yamawaki [2002]; Seamans [2013]). $R_{s t}^{0}$ is a dummy for year-of-reform which is set to 1 if state $s$ introduced reforms in year $t$. $R_{s t}$ is a post-reform dummy which is set to 1 if state $s$ had reformed in a year prior to year $t . f_{s}$ and $f_{t}$ are state and year fixed effects. ${ }^{19}$ The most parsimonious specification includes only these covariates in the analysis.

We then enrich our analysis by introducing more controls. We first introduce time-varying demographic controls for community $i$ at time $t$ in $\mathbf{X}_{\mathbf{i t}}$. These include variables that can affect the prices of cable service either by altering the demand from consumers (such as per capita income) or the costs to provide cable service (such as population density) or by altering the likelihood of market entry by competitors in that community (such as the growth rate of households) and local wage (for employees in the 'Information' industry (NAICS code: 51)) which controls for shifts in cost due to wage inflation (Savage and Wirth [2005]). Thereafter, in $\mathbf{Y}_{\mathbf{j t}}$, we also introduce variables corresponding to the characteristics of the cable company providing service in that community, viz., the number of subscribers it has at the national level, the share of subscribers it has at the state level, and its vertical affiliation with a content service provider. These variables are aimed at controlling for economies of scale, market power, and economies of scope in the provision of cable TV service.

Finally, in our strictest specification, to control for changes in composition or quality of service we introduce the log of number of channels offered on that tier of service as an additional control variable. In particular, this control ensures that

\footnotetext{
19 State level fixed effects generally yielded more conservative estimates and we use this as the baseline specification. Results using alternative levels of fixed effects, such as county fixed effects, or community fixed effects are presented in the robustness checks (see Sections V(iv) and V(v)).
} 
any observed change in prices are not offset by changes in the number of channels included in the service. ${ }^{20} \varepsilon_{i j s t}$ is the residual error term which accounts for all unobserved cost/demand shifters affecting prices. The identification assumption in the DID approach is that shifts in the unobserved variables are similar across states (so picked up by year effects) or fixed within states (so picked up by state fixed effects). We explore robustness to introducing more detailed fixed effects in Sections V(iv) and V(v) below.

Because the reforms are introduced at the state level, we cluster standard errors at the state level to account for inter-temporal correlation in the error terms (Bertrand, Duflo and Mullainathan [2004]). ${ }^{21}$

\section{V(ii). Baseline Price Effects}

V(ii)(a). Raw average price trends by reform status. Figures $2 \mathrm{a}$ and $2 \mathrm{~b}$ present the annual average by reform status for the prices over the period 2004-2010 for 'Basic' and 'Expanded Basic' services respectively. Figure 2a shows that average 'Basic' prices exhibit a significantly flatter trend in states that reformed between 2005 and 2008 relative to the states that did not reform, so that the relative price levels change from a premium in reformed states (prior to the reform) to a discount (after the reform) relative to the non-reformed states, consistent with the mean price changes documented in Table III. Also consistent with Table III, Figure $2 \mathrm{~b}$ shows no change in relative prices for 'Expanded Basic' service from 2004 to 2010 between reformed and non-reformed states. ${ }^{22}$ The results from the regression analysis discussed below allow us to control for a number of factors that could impact the simple means plotted in Figures $2 \mathrm{a}$ and $2 \mathrm{~b}$.

V(ii)(b). Regression results. Panel A of Table IV presents the results from the regression runs quantifying the effect of reform on the monthly price of 'Basic' service and Panel B of Table IV presents the same for 'Expanded Basic.' In column (1), there are no controls other than state and year fixed effects. Column (2) adds in the demographic controls, namely personal per capita income (and its square), population density (and its square), the rate of household growth, the fraction of the population aged between 5 and 18 (as a control for the age structure of the population) and the local wage for NAICS code, 51 (Information). All of these controls are available at the county level and are introduced in log form. In addition, we also include two additional controls for the size of the average cable system (measured in terms of number of subscribers per cable

\footnotetext{
${ }^{20}$ We explore robustness to additional controls for quality of service in Section V(v) below.

${ }^{21}$ We also clustered in both the state and time dimensions for our preferred specifications, following Petersen [2009]. We found standard errors are smaller than those we obtain by clustering only at the state level. Given that, to be conservative, we report results clustering on just the cross-sectional (state) dimension.

${ }^{22}$ There is a somewhat surprising increase in prices in reformed states for one year in 2008, but this reverses in 2009, so by 2010 the prices are back at same levels.
} 


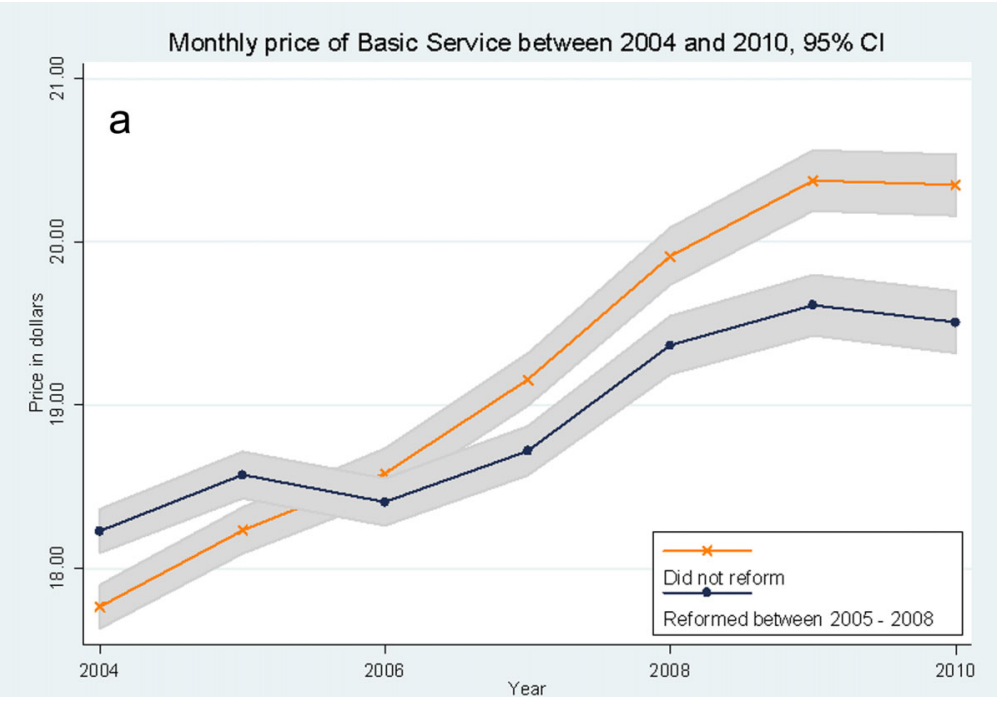

Figure 2a

Trend in Price of 'Basic' Service

Notes: Data on cable prices is taken from successive issues of Warren's TV Factbook (2004-2010). Price data is available at the level of each individual community. Generally the boundaries of a cable community correspond to that of a municipality, though there may be multiple cable communities within a single municipality and vice versa. There are approximately 30,000 cable communities in the U.S. The monthly price data used in this graph pertains to that of 'Basic' service. This price excludes all installation charges and any charges associated with equipment rental and reflect the monthly subscription charges for an individual consumer. 'Basic' service is the level of cable television service that must be taken by all cable television subscribers. The content of basic cable service varies among cable systems but, pursuant to the Communications Act, must include all local television signals and public, educational, and governmental access channels and, at the discretion of the cable operator, may include other video services. The list of states which reformed their franchising process between 2005 and 2008 along with the list of states which did not reform is provided in Table I, and shown graphically in Figure 1.

system in the state) and the Designated Market Area (DMA) rank. DMA rank measures the strength of the local television market and affects demand by proxying for alternative sources of entertainment in the local system area (Crawford [2000]). Column (3) adds controls for the market structure, viz. the total number of subscribers the company has nationally, the share of state subscribers for the company providing service in that community, and a dummy that is set to 1 whenever the local company is vertically affiliated with a content service provider. Finally, column (4) adds controls for the quality of service, measured in terms of the log of number of channels. For brevity, Table IV (and all subsequent tables) include only the coefficients of interest corresponding to price effects in the year of reform and in the years following the enactment of reform for the states that reformed between 2005 and 2008. Full results with coefficients on the control 


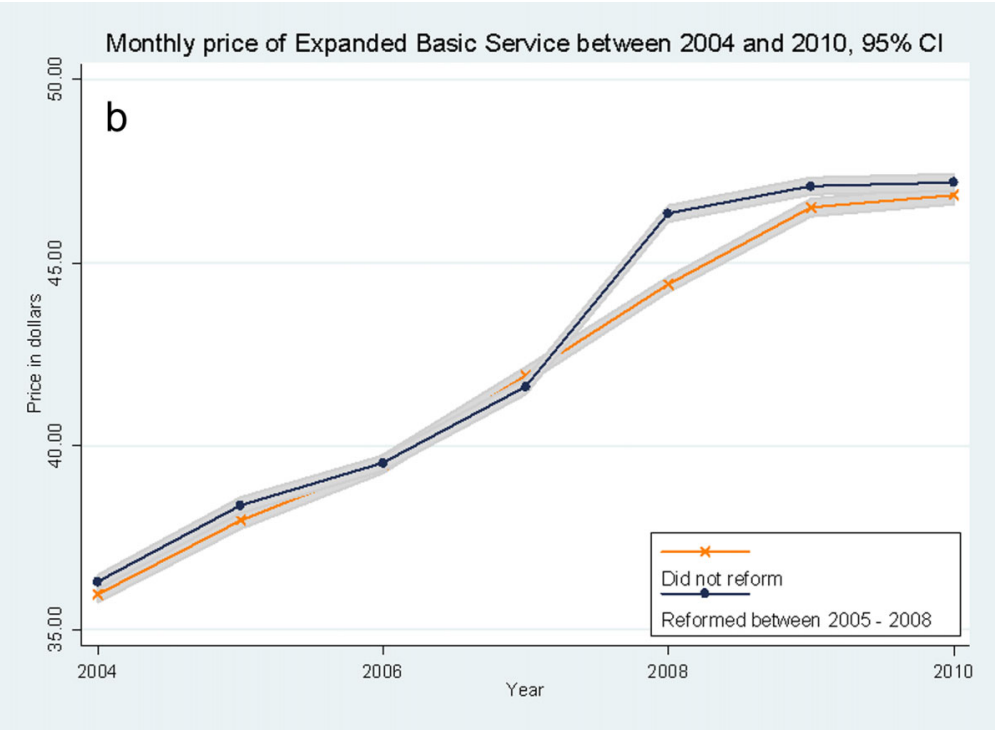

Figure 2b

Trend in Price of 'Expanded Basic' Service

Notes: Data on cable prices is taken from successive issues of Warren's TV Factbook (2004-2010). Price data is available at the level of each individual community. Generally the boundaries of a cable community correspond to that of a municipality, though there may be multiple cable communities within a single municipality and vice versa. There are approximately 30,000 cable communities in the U.S. The monthly price data used in this graph pertains to that of 'Expanded Basic' service. This price excludes all installation charges and any charges associated with equipment rental and reflect the monthly subscription charges for an individual consumer. 'Expanded Basic' service offers additional video channels on one or more service tiers and includes most of the better-known national cable television networks. The list of states which reformed their franchising process between 2005 and 2008 along with the list of states which did not reform is provided in Table I, and shown graphically in Figure 1.

variables are available on request from the authors. The specifications used in Table IV are used through the rest of the paper for all regressions which involve prices of either 'Basic' or 'Expanded Basic' service.

Depending on which specification is used, we see that the monthly price of 'Basic' service is lower by 5.5 to $6.8 \%$ in states that have reformed their franchising process as compared to states that have not. Given that the average price of 'Basic' service in 2010 is about $\$ 20 /$ month (see Table III), the percentage decline translates to a drop of $\$ 1.10$ to $\$ 1.36$ per month per subscriber or $\$ 13.20$ to $\$ 16.32$ per year per subscriber for 'Basic' service.

In contrast to the robust evidence of decline in price of 'Basic' service, we do not observe any statistically significant change in the price of 'Expanded Basic' service in any specification in Panel B of Table IV. In columns (1) and (2), the coefficient on the 'Post-reform' dummy is close to zero; in columns (3) 
TABLE IV

DiD Effect of Reform on Price of ‘Basic’ and ‘Expanded Basic’ Tiers of Service

\begin{tabular}{lcccc}
\hline & $(1)$ & $(2)$ & $(3)$ & $(4)$ \\
\hline Panel A: 'Basic' service & & & & \\
Year of reform & $-0.0229^{* *}$ & $-0.0237^{*}$ & $-0.0264^{+}$ & -0.0241 \\
Post-reform & $(-2.06)$ & $(-1.95)$ & $(-1.48)$ & $(-1.39)$ \\
& $-0.0553^{* * *}$ & $-0.0603^{* * *}$ & $-0.0684^{* * *}$ & $-0.0578^{* *}$ \\
Number of observations & $(-2.95)$ & $(-2.85)$ & $(-2.94)$ & $(-2.26)$ \\
R-squared & 211,500 & 183,253 & 181,704 & 181,637 \\
Panel B: 'Expanded Basic' service & 0.12 & 0.14 & 0.27 & 0.44 \\
Year of reform & & & & 0.00144 \\
& -0.00435 & -0.00776 & -0.00236 & $(0.066)$ \\
Post-reform & $(-0.21)$ & $(-0.35)$ & $(-0.10)$ & 0.0212 \\
Number of observations & 0.00134 & 0.00358 & 0.0171 & $(0.63)$ \\
R-squared & $(0.042)$ & $(0.11)$ & $(0.50)$ & 120,637 \\
Demographic controls & 137,180 & 121,369 & 120,653 & 0.27 \\
Controls related to market structure & 0.18 & 0.20 & 0.23 & $\mathrm{Y}$ \\
Control for number of channels & $\mathrm{N}$ & $\mathrm{Y}$ & $\mathrm{Y}$ & $\mathrm{Y}$ \\
& $\mathrm{N}$ & $\mathrm{N}$ & $\mathrm{N}$ & $\mathrm{Y}$ \\
\hline
\end{tabular}

Notes: Data on cable prices are taken from successive issues of Warren's TV Factbook (2004-2010). Price data are available at the level of each individual community. Generally the boundaries of a cable community correspond to that of a municipality, though there may be multiple cable communities within a single municipality and vice versa. There are approximately 30,000 cable communities in the U.S. All regressions include state and year fixed effects. Demographic controls: Personal per capita income (and its square), population density (and its square), the rate of household growth, the fraction of the population aged between 5 and 18, and the local wage. All of these controls are available at the county level and are introduced in log form. They also include controls for the size of the average cable system (measured in terms of number of subscribers per cable system in the state) and the DMA rank. Controls related to market structure: Number of national subscribers, the share of state subscribers for the company providing service in that community, and a dummy that is set to 1 whenever the local company is vertically affiliated with a content service provider. Control for number of channels include log of number of channels provided on that tier of service. 'Year of reform' is a dummy variable that equals 1 for states which reformed between 2005 and 2008 in their year of reform. Thus, for example, for California which reformed in 2007, this dummy variable assumes the value 1 for that year and that year alone. 'Post-reform' is a dummy variable that equals 1 for states which reformed between 2005 and 2008 in the years following the reform. Thus, for example, for California, this variable assumes the value 1 for years 2008 through 2010. 'Basic' service is the level of cable television service that must be taken by all cable television subscribers. The content of basic cable service varies among cable systems but, pursuant to the Communications Act, must include all local television signals and public, educational, and governmental access channels and, at the discretion of the cable operator, may include other video services. 'Expanded Basic' service offers additional video channels on one or more service tiers and includes most of the better-known national cable television networks. The price data provided in this table exclude all installation charges and any charges associated with equipment rental and reflect the monthly subscription charges for an individual consumer. Robust $t$ statistics, clustered by state, in parentheses $+\mathrm{p}<0.15, * \mathrm{p}<0.10, * * \mathrm{p}<0.05, * * * \mathrm{p}<0.01$.

and (4) after addition of demographic controls and log number of channels, the estimated coefficient continues to be positive but is not significant in any of the specifications. $^{23}$

${ }^{23}$ It could be noted in Table IV that the number of observations for 'Expanded Basic' prices is lower, reflecting availability of data in the Warren's database. We checked to see if sample differences were salient in explaining different results for 'Expanded Basic,' by estimating results for 'Basic' service on the 'Expanded Basic' sample. We found the results qualitatively similar, with coefficient magnitudes only slightly lower - a $4.8 \%$ decline in the column (4) specification compared to a $5.8 \%$ decline in the full sample. Thus differences in the sample do not appear to explain the differences in results for 'Expanded Basic.' Also, we checked and verified that the proportion of observations for 
In the sections below, we check robustness of the finding of a post-reform decline in the price of 'Basic' service to a number of different concerns.

\section{V(iii). Checking for Pre-Existing Trends}

A fundamental concern in any DID analysis is the possibility that the observed mean effects are driven by differences in pre-existing trends. In particular, a declining trend in prices for 'Basic' service in those states that reformed their franchising process between 2005 and 2008 could lead to the observed mean decline documented in Table IV. We address this concern in two ways.

First, in Appendix Table A2, we specifically examine the trend in price of 'Basic' service prior to the reforms. ${ }^{24}$ The regressions include only observations prior to the reforms, and we include dummies for two years and one year before the reform - all other pre-reform years are absorbed into the constant. The results reveal that, once we add in demographic controls (column (2)), there is no significant declining trend (as the coefficients on Reform year - 1 and Reform year -2 are both relatively small and statistically insignificant). Once we add in additional controls for market structure and number of channels (column (4)), the magnitude of the coefficients on Reform Year - 2 and Reform year - 1 are both very small and statistically insignificant. Thus relative to the period prior to two years before the reform, the price in the two years just before the reforms is within $0.2 \%$ in Reform year - 2 and within $0.7 \%$ in Reform year - 1 , which suggests no prior declining trend in prices of 'Basic' service.

We expand on this to estimate and plot coefficients on an index relative to year of reform, as suggested in Angrist and Pischke ([2009], Chapter 5). In particular, we estimate the following regression:

$$
p_{i j s t}=\alpha+\sum_{k=-4}^{5} \lambda^{k} \cdot R_{s t}^{k}+\boldsymbol{\beta}_{3} \cdot \mathbf{X}_{\mathbf{i t}}+\boldsymbol{\beta}_{4} \cdot \mathbf{Y}_{\mathbf{j t}}+f_{s}+f_{t}+\varepsilon_{i s t}
$$

where all the variables are as defined in (1), and index $R_{s t}^{k}$ equals one if state $s$ in year $t$ is $k$ years from the reform for states that reformed between 2005 and 2008; for example, for California, which reformed in $2007, R_{s t}^{-2}$ is equal to one for year 2005 and zero otherwise. ${ }^{25}$

In Figure 3, we plot the coefficients $\lambda^{k}$ for $k=-3$ to $k=+4$, to observe trends before and after the year of reform, conditioning on demographic controls, market structure variables, and the number of channels. As the figure suggests, there were no marked pre-existing trends prior to the enactment of these reforms;

'Expanded Basic' was very similar (66\% and 63\% respectively) for states that reformed between 2005 and 2008 and non-reformed states.

${ }^{24}$ All Appendix Tables are presented in the online Appendix.

${ }^{25}$ For the states that reformed prior to 2005 we set the index to 20 so that they are effectively excluded from the range of indices plotted in the figure. 


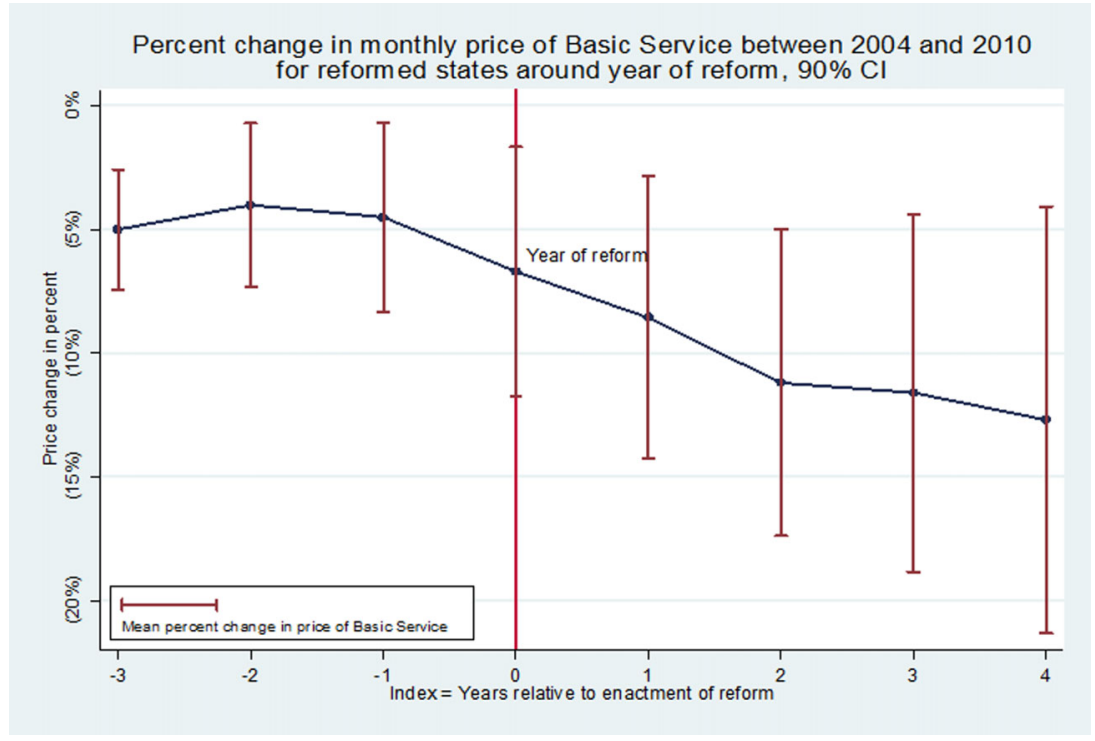

Figure 3

Trend in Price of 'Basic' Service in Reformed States, around Reform Year

Notes: The per cent numbers on the vertical axis are log points relative to prices for the year - 4 (i.e., four years prior to reform). The underlying regression includes all controls included in column (4) of Table IV including state and year fixed effects, controls for market structure, demographic controls and control for number of channels. See notes to Table IV for details on individual control variables. Data on cable prices is taken from successive issues of Warren's $T V$ Factbook (2004-2010). Data plotted are for three years prior to the enactment of reform and for four years after the enactment of reform. This graph is based on all communities, including states which reformed between 2005 and 2008, states which did not reform, and states which reformed prior to 2005.

in fact the trend over the period -3 to -1 remains remarkably flat. Figure 3 also shows there is beginning of a decline in prices in the year of the reform, and then within three years of the passage of these reforms, the price of 'Basic' service is significantly less than its level prior to the enactment of the reforms and it continues to be lower subsequently.

To see if prior trends could explain the lack of results for 'Expanded Basic' service, we undertook the same test as in Table A2 for this tier. The results, presented in Appendix Table A3, show that there were no differential trends in 'Expanded Basic' price in the pre-reform period in reformed states relative to non-reformed states. In fact, the differential effects are very small, statistically insignificant, and less than $1.6 \%$ across all the different specifications.

\section{V(iv). Potential Data Quality Issues}

The choice of Warren's Factbook as the primary source of cable price and quantity (number of subscribers) data for our paper stems from its widespread use in 
empirical studies of the industry (e.g. Rubinovitz [1993]; Goolsbee and Petrin [2004]; DellaVigna and Kaplan [2007]; Seamans [2013]) and because of its richness: it includes information on monthly prices and installation fees, the number of consumers subscribing to the various tiers, and the specific channels available on each tier of service for each individual cable system. No other source that we are aware of provides such rich data. Furthermore, the cable systems included in Warren's database cover 96\% of all cable subscribers nationwide (FCC [2009], p. 198) providing us with nearly universal coverage of all cable systems in the country, and as noted earlier (footnote 15), it is used extensively by the FCC.

Crawford and Yurukoglu [2012] who also use the Warren's Factbook data however point to potential data quality concerns about time series variation within this dataset. In particular, the authors document that observations for cable systems in the Factbook are often not updated. In recent work, Martin and Yurukoglu [2016] document how findings in a prominent paper (DellaVigna and Kaplan [2016]) are significantly impacted by use of an alternative dataset (Nielsen) that has more updated information on channel availability. ${ }^{26}$ However, as Crawford and Yurukoglu [2012] also note, the lack of updates to the Factbook data is likely to induce classical measurement error, so that 'unobservable characteristics of cable systems that impact whether an entry in the Factbook is up-to-date' are not likely to be correlated with 'the demand they face and/or their pricing behavior.' Likewise, we also believe that it would be unlikely for measurement error from infrequent updates to be correlated with the reform status of the state in such a way as to systematically bias us towards finding the negative effects we document for 'Basic' service prices. ${ }^{27}$

Nevertheless, in order to address the concerns regarding data quality, we undertake three alternative tests. In the first test, we only include communities for which there is at least one change in price for that tier of service over the sample period. Our second test examines the average price for each tier of service in the pre-reform and in the post-reform period using only one observation per period (pre-reform and post-reform). In our third and final test, we explore alternative specifications in which we introduce cable system fixed effects (identical to principal community fixed effects) or community-level fixed effects so that locations where entries were not updated get absorbed, and only communities with changes over time contribute to the estimate. Results from these three tests are provided in Panel A of Table V for 'Basic' service and in Panel B of that table for 'Expanded Basic' service.

\footnotetext{
${ }^{26}$ Specifically Martin and Yurukoglu [2016] document severe mismeasurement of Fox News availability in DellaVigna and Kaplan [2007]; they find that nearly $40 \%$ of the 'control group,' the locations that DellaVigna and Kaplan consider as not having cable access to Fox News in 2000, did in fact have cable access to Fox News, with the mismeasurement induced by non-updation of data in the Warren's TV Factbook database.

${ }^{27}$ We also verified empirically that the likelihood an observation is updated in the Warren's dataset is indeed uncorrelated with the reform status of the state. Nevertheless, as noted by a referee, if there were a true relative downward trend in reformed states, non-updation would bias our estimates towards zero, so the noisy null effect on 'Expanded Basic' could be induced by measurement error.
} 
TABLE V

Robustness Checks to Address Potential Data Quality Concerns

(1)

(2)

(3)

(4)

Panel A: Effect of reform on price of 'Basic' service

\begin{tabular}{|c|c|c|c|c|}
\hline Base Specification & $\begin{array}{l}-0.0553^{* * *} \\
(-2.95)\end{array}$ & $\begin{array}{l}-0.0603^{* * *} \\
(-2.85)\end{array}$ & $\begin{array}{l}-0.0684^{* * *} \\
(-2.94)\end{array}$ & $\begin{array}{l}-0.0578^{* *} \\
(-2.26)\end{array}$ \\
\hline $\begin{array}{l}\text { Test 1: Including only cable head-ends where } \\
\text { there is at least one price change } \\
\text { Test 2: Considering the average price in the } \\
\text { pre-reform and in the post-reform period and } \\
\text { including only one observation for each period }\end{array}$ & $\begin{array}{l}-0.101^{* * *} \\
(-3.49) \\
-0.0495^{* * *} \\
(-2.77)\end{array}$ & $\begin{array}{l}-0.101^{* * *} \\
(-3.18) \\
-0.0632^{* * *} \\
(-2.92)\end{array}$ & $\begin{array}{l}-0.0953^{* * *} \\
(-2.83) \\
-0.0688^{* * *} \\
(-3.17)\end{array}$ & $\begin{array}{l}-0.0903^{* * *} \\
(-3.09) \\
-0.0406^{*} \\
(-2.21)\end{array}$ \\
\hline $\begin{array}{l}\text { Test 3: Introducing alternative Fixed Effects at the } \\
\text { - Cable system level } \\
\text { - Community level }\end{array}$ & $\begin{array}{l}-0.0618^{* * *} \\
(-3.14) \\
-0.0581^{* * *} \\
(-2.78)\end{array}$ & $\begin{array}{l}-0.0625^{* * *} \\
(-3.20) \\
-0.0515^{* *} \\
(-2.59)\end{array}$ & $\begin{array}{l}-0.0651^{* * *} \\
(-3.21) \\
-0.0534^{* *} \\
(-2.61)\end{array}$ & $\begin{array}{l}-0.0635^{* * *} \\
(-3.32) \\
-0.0533^{* * *} \\
(-2.89)\end{array}$ \\
\hline \multicolumn{5}{|c|}{ Panel B: Effect of reform on price of 'Expanded Basic' service } \\
\hline $\begin{array}{l}\text { Base Specification } \\
\text { Test 1: Including only cable head-ends where } \\
\text { there is at least one price change }\end{array}$ & $\begin{array}{l}0.00134 \\
(0.042) \\
0.0215 \\
(0.63)\end{array}$ & $\begin{array}{l}0.00358 \\
(0.11) \\
0.0305 \\
(0.98)\end{array}$ & $\begin{array}{l}0.0171 \\
(0.50) \\
0.0318 \\
(1.07)\end{array}$ & $\begin{array}{l}0.0212 \\
(0.63) \\
0.0383 \\
(1.33)\end{array}$ \\
\hline $\begin{array}{l}\text { Test 2: Considering the average price in the } \\
\text { pre-reform and in the post-reform period and } \\
\text { including only one observation for each period }\end{array}$ & $\begin{array}{l}-0.00657 \\
(-0.29)\end{array}$ & $\begin{array}{l}-0.00487 \\
(-0.20)\end{array}$ & $\begin{array}{l}0.00977 \\
(0.37)\end{array}$ & $\begin{array}{l}0.0197 \\
(0.75)\end{array}$ \\
\hline $\begin{array}{l}\text { Test 3: Introducing alternative Fixed Effects at the } \\
\text { - Cable system level } \\
\text { - Community level }\end{array}$ & $\begin{array}{c}-0.00149 \\
(-0.045) \\
0.00280 \\
(0.078)\end{array}$ & $\begin{array}{l}0.000352 \\
(0.013) \\
0.00678 \\
(0.21)\end{array}$ & $\begin{array}{l}-0.000153 \\
(-0.0055) \\
0.00650 \\
(0.20)\end{array}$ & $\begin{array}{l}-0.000792 \\
(-0.029) \\
0.00409 \\
(0.13)\end{array}$ \\
\hline $\begin{array}{l}\text { Demographic controls } \\
\text { Controls related to market structure } \\
\text { Control for number of channels }\end{array}$ & $\begin{array}{l}\mathrm{N} \\
\mathrm{N} \\
\mathrm{N}\end{array}$ & $\begin{array}{l}\mathrm{Y} \\
\mathrm{N} \\
\mathrm{N}\end{array}$ & $\begin{array}{l}\mathrm{Y} \\
\mathrm{Y} \\
\mathrm{N}\end{array}$ & $\begin{array}{l}\mathrm{Y} \\
\mathrm{Y} \\
\mathrm{Y}\end{array}$ \\
\hline
\end{tabular}

Notes: Coefficients presented in columns (1) through (4) correspond to various combinations of control variables. The dependent variable in Panel A (Panel B) is the monthly price data for accessing 'Basic' ('Expanded Basic') service. This price excludes all installation charges and any charges associated with equipment rental and reflect the monthly subscription charges for an individual consumer. All regressions include year fixed effects and state fixed effects unless mentioned to the contrary. Demographic and market-structure controls are as in Table IV. Reported estimates are coefficients on the Post-reform dummy, which is a variable that equals 1 for states which reformed between 2005 and 2008 in the years following the reform (see Table I for a full list). For test 2, for states that never reformed or states that reformed prior to 2005, we consider the average price over the period 2004-2007 as the 'pre-reform' price and the average price over the period $2008-2010$ as the 'post-reform' price. Robust $t$ statistics, clustered by state, in parentheses $+\mathrm{p}<0.15, * \mathrm{p}<0.10,{ }^{* *} \mathrm{p}<0.05, * * * \mathrm{p}<0.01$.

The baseline results continue to hold in each of the three tests described above; in particular, we observe a negative and statistically significant decline in the price of 'Basic' service following the enactment of the reforms, while there are no statistically significant changes in the price of 'Expanded Basic' service. In fact, the results in the second row of Panel A suggests that when we limit the estimation to only those observations where there is at least one change in price between the period 2004-2010, the decline in the monthly price of 'Basic' service following the reforms is substantively larger, in the range of $9.0-10.0 \%$ compared to the 5.5-6.8\% we observe in the baseline specifications. This suggests that measurement error is a concern here but that measurement error is likely to induce a downward bias on our coefficient of interest. 
Finally, we also attempted to obtain alternative sources of data to examine the robustness of the results that we report in the paper using Factbook data. We were fortunate to obtain hand-collected data, very graciously shared with us by Ali Yurukoglu, collated from (a) prices posted on websites and saved in the Internet Archive (b) prices posted in newspapers, and (c) those provided in 'rate cards' by cable companies. However, two important differences between Warren's and the hand-collected data limit the comparability of analysis across the two data sources. First, the number of observations is significantly lower in the hand-collected data, especially for the 'Basic' service tier for which we find declines in the Warren's database. Specifically, the hand-collected data have only 1,709 observations for the price of 'Basic' service for the entire sample period 2004-2010 whereas, using the Warren's Factbook, we have 44,483 observations for the price of 'Basic' service at the cable system level, or over 25 times more than in the hand-collected data. Second, there are systematic differences between the coverage of communities in the hand-collected data and those in the Factbook. For example, the median population density of counties for which price data exist for either 'Basic' or 'Expanded Basic' service in the hand-collected data is about 550 persons per sq. mile, whereas the population density of counties for which price data exist in the Factbook is about 100 persons per sq. mile. Consistent with the FCC [2009] quote on the extensive coverage for Warren's, the population density for the country is about 89 persons per sq. mile, closer to that of the Factbook sample. Similarly, the median Designated Market Area (DMA) rank (which measures the strength of the local television market) in the hand-collected data is 29 compared to 58 in the Factbook data.

Notwithstanding these concerns limiting comparability of the two data sources, we examined the effects of these reforms using the hand-collected data (Appendix Table A4). Consistent with our baseline results, the increase in average price for 'Basic' service was $\$ 2.67$ less per month in states that reformed between 2005 and 2008 compared to states that never reformed. Considering the average price for 'Basic' service over this period, these summary statistics suggest that the reforms resulted in a substantial $21 \%$ decline in the price of 'Basic' service over the period 2004-2010. By contrast, there was a decline of only $\$ 1.57$ per month (or $4 \%$ ) in the price of 'Expanded Basic' service using these data. ${ }^{28}$

Beyond examining the summary statistics, we also examined the effects of the reforms in a regression set-up as in specification (1). Unfortunately, the

\footnotetext{
${ }^{28}$ One point to note is that, comparing Appendix Table A4 to Table III, while the raw average prices levels for the 'Basic' service in Ali's hand-collected data are close to that in the Warren's data (e.g., average price of $\$ 19.51$ in reforming states for 2010 in Warren's compared to $\$ 20.77$ in Ali's data), the mean price for 'Expanded Basic' is significantly lower in the Warren's data (e.g., average price of $\$ 47.20$ in reforming states for 2010 in Warren's compared to $\$ 56.36$ in Ali's data), suggesting potential mismeasurement may be more severe for 'Expanded Basic.' As we acknowledge in the conclusion, this measurement error could be one explanation for the null effect of reforms we find on the price of 'Expanded Basic' service.
} 
estimates were noisy and not statistically significant but the standard errors were large enough that they did not rule out the effects we report in this paper on the basis of Factbook data. These additional results are available from the authors on request. Because the Warren's Factbook data are more representative of the country as a whole, we focus primarily on that dataset throughout this paper.

Further, the number of robustness checks in the next section and the number of additional analyses we undertake (e.g., of entry in Section VI(i), of limit pricing in Section VI(ii), a triple-difference test of the effect of increased threat of entry on prices and subscriber numbers in Section VII), provide a series of sharp additional checks of the soundness of the baseline results. In particular, measurement error in prices in the Warren's data is unlikely to be related to potential error in how entry is measured in the Warren's data, or in measurement of Telco entry which was hand-collected by us. Similarly, we believe the triple difference analysis in Section VII, which examines variation of prices in communities adjacent to overbuilders relative to other communities across reformed and non-reformed states, is highly unlikely to be biased by measurement error from prices being infrequently updated.

\section{V(v). Decline in Prices for 'Basic'Service: Robustness Checks}

In this section, we check robustness of the finding that prices declined for 'Basic' service using a number of alternative tests. Results for tests RC1 to RC9 are summarized in Appendix Table A5; results for the remaining tests are presented in other Appendix tables.

$\mathrm{V}(\mathrm{v})(\mathrm{a}) . \quad$ RC1: Alternative controls for service quality. The observed reduction in price is economically meaningful only if it was not offset by reduction in the quality of the service offering. In column (4) of Table IV, our specification includes the log of number of channels, which controls for adjustments in terms of addition or deletion of channels. However, cable operators could respond by dropping more popular channels and adding less popular ones, so that the quality of offering declines while the total number of channels stays the same (For example, Crawford [2000] finds that cable operators changed composition of offerings in response to the 1992 Cable Act). To address this concern, in rows 2, 3 and 4 of Table A5, we include alternative measures to control for changes in composition of 'Basic' service. In row 2, we include log of the number of channels that are distributed nationally to systems via satellite (also known as satellite channels), in row 3 we include log of the number of channels that are within the top 10 most popular channels, and finally in row 4 we include log of the number of channels that are within the top 20 most popular channels. ${ }^{29}$

\footnotetext{
${ }^{29}$ Satellite channels include some of the most easily recognizable names in cable, such as MTV, CNN, and ESPN. The list of most popular channels is drawn from Crawford and Yurukoglu [2012] which in turn, is based on ratings from Nielsen Media. For Nielsen Media, the ranking of channels 
We find the baseline results to be robust; in fact in rows 3 and 4, including controls for the top 10 and top 20 channels yields stronger results, suggesting that the composition changes in programming quality in reformed states may have reinforced, rather than offset, the decline in prices.

$\mathrm{V}(\mathrm{v})(\mathrm{b}) . \quad$ RC2: Including installation charges. The economic significance of the observed decline in prices, particularly for new consumers switching into cable, could be affected by concurrent changes to installation fees. To check whether changes to installation fees offset the decline in monthly price, we look at the net price of receiving 'Basic' service in which we amortize the installation fees over a 12-month period and add that to the monthly price. Results for net price of receiving service are presented in row 5 of Table A5. While the price drop reduces slightly, it remains statistically significant and ranges from 4.6 to $5.6 \%$. It appears that installation fees increased slightly in reformed states, but note that because the average cable consumer is likely to have her installation for a period that is longer than 12 months, amortizing installation fees over a 12 -month period is likely to understate the decline in prices brought about by the reforms in these specifications.

$\mathrm{V}(\mathrm{v})(\mathrm{c})$. RC3: Long differences. If there is some lag in the response to the reforms, or if incumbents changed behavior prior to the reforms once passage of the law became more certain, then the DID regressions could give smaller estimates than the true long-run effects of the reforms. To get at the more longrun effects, we use a long difference approach (similar to Donohue and Levitt, [2001]). In particular, we rerun baseline regressions including only data for the starting and ending years of the sample, i.e., for 2004 and 2010. As expected (and consistent with the pattern in Figure 3), the estimates in row 6 of Table A5 are uniformly larger, ranging between $7.5-9.8 \%$ suggesting that the longer run impact of these reforms may be larger than the about $6 \%$ estimate we find in our baseline analysis.

$\mathrm{V}(\mathrm{v})(\mathrm{d}) . \quad$ RC4: Balanced panel. The results thus far have been estimated on all available data. Because of consolidation of cable systems over the years, there are fewer cable systems in the later years of the sample, so that the panel in the baseline analysis is unbalanced. To ensure results are not driven by compositional effects, we examine robustness to using a balanced panel of communities that were present in all seven years of the data. The estimates (in row 7 of Table A5) yield somewhat stronger results (a decline of about 7.1-8.1\%) relative to the baseline. given that we have data from 2004 to 2010 , this corresponds to roughly the mid-point of our sample period. 
$\mathrm{V}(\mathrm{v})(\mathrm{e}) . \quad$ RC5: Alternative fixed effects. The baseline regression includes state fixed effects in every regression, as the effects of state-level reforms are identified from cross-state and time variations, and hence the main omitted variables that concern us are state-level variables. Nevertheless, we explore an alternative specification in which we introduce county fixed effects. We continue to see a drop in the price of 'Basic' service by approximately 6\%. Results involving cable system fixed effects (identical to principal community fixed effects) or community level fixed effects were presented earlier in Table $\mathrm{V}$ and considered with these results involving county fixed effects, we see that the price decline for 'Basic' service is robust to the inclusion of various alternative fixed effects.

V(v)(f). RC6: Principal communities only. The Warren's data includes information on all communities served by a cable head-end, with the location of the cable head-end designated as the principal community. Because in non-reformed states and in reformed states prior to the reform, the local franchising regulations operated at the community level, our baseline analysis uses observations on all communities. In this robustness check, we exclude all these communities that are served by the same cable system and limit our analysis only to the principal communities where the cable head-ends are located. Even though this causes our sample size to drop to about $20 \%$ of the original sample size, our results hold with somewhat smaller magnitudes with this sub-sample as well (in row 9 of Table A5).

$\mathrm{V}(\mathrm{v})(\mathrm{g})$. RC7: Alternative control groups. In the baseline analysis, we have included the four states which reformed prior to 2005 (Alaska, Hawaii, Rhode Island and Vermont). Although we allow the effects for these states to be different in the post reform period in the baseline analysis, we explore the robustness of our results to excluding these four states altogether (in row 10 of Table A5), and find the estimates similar to the baseline.

Further, in the baseline, the control group of non-reformed states includes the states of Alabama, Utah and Virginia which have laws on their books prohibiting municipal electric utilities (MEU's) from cross-subsidizing their entry into the cable TV business. As Seamans [2012] shows, incumbent cable systems located in such states are less likely to upgrade equipment even though they may face entry from a municipal entrant because the latter are legally prevented from cross-subsidizing entry into the cable TV business. In order to preclude the results from being affected by these states, we exclude these three states from the analysis (in row 11 of Table A5), and find that the results are largely unchanged.

Finally, the control group of non-reformed states includes the states of Alabama, Kentucky, Minnesota, New Hampshire and Oklahoma which have 'level playing field' laws on their books. As Hazlett [2007] argues, these level playing field laws impose far harsher costs on competitors than on the incumbent and have the effect of forestalling competitive entry into the local cable market. Because we expect the existence of such laws on the books to impact the price 
of cable service in such states, we examine the robustness of the results to the exclusion of these states from the control group (in row 12 of Table A5) and find the results to be similar to baseline.

$\mathrm{V}(\mathrm{v})(\mathrm{h}) . \quad$ RC8: Distinguishing multi-system operators from smaller firms. The two new entrants during the period of analysis, Verizon and AT\&T, overlapped disproportionately with a number of large multi-system operators (MSO's) who were growing and becoming more efficient during this time period. Therefore, in this robustness check, we introduce company-year fixed effects for each of the five largest cable operators (Comcast, Time Warner Cable, Charter Communications, Cox Communications, and Cablevision Systems) along with a dummy variable for each operator. Our results are robust to the inclusion of such fixed effects in the regressions and suggest that price declines following reforms were across the board and not confined exclusively to the largest MSO's.

V(v)(i). RC9: Analysis within states with Telco competitor presence. Here we check the robustness of the results to using only those states where key competing Telcos (Verizon and AT\&T) had a presence. If these Telcos were present disproportionately in reformed states, and were getting more aggressive, then the baseline estimates may be confounded by the impact of increased aggressiveness on the part of Verizon and AT\&T. The results in row 14 of Table A5 suggest that the magnitude of the effects are similar within states with the presence of Verizon or AT\&T, suggesting that the baseline effects were not driven by a general increase in Telco aggressiveness, and that the reforms resulted in lower prices of 'Basic' service even within states where either Verizon or AT\&T were present.

V(v)(j). RC10: Falsification test using electricity prices. It could be the case that the price decline for 'Basic' service is driven by relatively larger price declines in these states due to other reasons, or because of increases in prices in the non-reformed states (driven by say, increases in income or changes in business climate in ways not captured by our demographic controls). To address this concern, we conduct a falsification test in which we consider the change in the average electricity prices paid by residential, commercial, and industrial consumers over the same period of time from 2004 to 2010 across all 50 states. If other shocks were negatively impacting prices in reformed states or positively impacting prices in non-reformed states, then those should also be reflected in the electricity prices paid by residential, commercial, and industrial consumers. As the results in Appendix Table A6 show, we find no evidence of a relative decline for either residential or commercial or industrial electricity prices. In fact, the coefficient on the 'Post Reform' dummy is positive, very small (averaging less than 1\%) and statistically indistinguishable from zero in all the four specifications of this table. 
$\mathrm{V}(\mathrm{v})(\mathrm{k})$. RC11: Effect on number of subscribers. In Appendix Table A7, we check if observed price declines led to increases in the number of subscribers for 'Basic' service. The results suggest an increase in the number of consumers who subscribe to just the 'Basic' tier which is consistent with the observed price decline. However, the effect is not statistically significant. There appears to be a greater magnitude of increase $(7.4 \%)$ in column (3), but this appears to be explained partially by changes to the number of channels, as the magnitude declines to $2.8 \%$ in column (4). Also, it appears that during the same time, despite no evidence of a decline in price, there is a statistically insignificant increase in the number of subscribers to 'Expanded Basic' service.

$\mathrm{V}(\mathrm{v})(\mathrm{l})$. Robustness checks for price of 'Expanded Basic'service. To examine if the finding of a null effect on the price of 'Expanded Basic' is robust, we also undertake all of the checks RC1 to RC9 for 'Expanded Basic.' Results are presented in Appendix Table A8; we find the null effect result for 'Expanded Basic' remarkably robust across all the different checks.

\section{ROLE OF ENTRY}

The stated objective of the reforms allowing for franchising at the state level was to increase the incidence of competition in the localized cable television markets and bring lower prices to consumers. ${ }^{30}$ However, as discussed in Section III, the theoretical effect of lowering of entry barriers in this context is ambiguous, given that entry still required significant upfront (sunk) investments, especially for the 'last mile' connections to residences (e.g., see Wagter [2010]). In particular, as discussed earlier, in a model with Bertrand price competition in the second stage (Sutton, [1991], Chapter 2), rational firms would not enter as long as upfront costs were greater than zero, as they anticipated zero profits in the post-entry stage. Thus, whether actual entry occurred is an interesting empirical question.

In this section we examine two questions. First, in Section VI(i), we examine whether the reforms spurred greater entry, especially by Telcos, who lobbied for the passage of the reforms in many states. (e.g., see news articles by Sher [2008] and Haugsted [2006]). Second, in Section VI(ii), we examine whether observed baseline price results were driven by post-entry price declines, or whether there is evidence for ex ante price declines even without entry (as predicted by Milgrom and Roberts [1982b] or Klemperer [1987]).

One hurdle to studying entry is that data for Telcos offering TV services is not included in the Warren's database. Therefore, data on these companies had to be hand-collected separately. We focused on the two major players - AT\&T and Verizon - as these two together accounted for over $90 \%$ of the market share of

\footnotetext{
${ }^{30}$ E.g., Governor Jon Corzine. The then Governor of New Jersey's statement when signing the relevant bill stated: 'The power of competition can improve quality and lower prices. Under the legislation signed today authorizing new cable franchises, New Jersey cable television customers will soon see the benefits of competition.' (U.S. Fed News, August 2006)
} 
Telcos in the Cable TV market in 2010 according to the Frost \& Sullivan online database. ${ }^{31,32}$ There are two limitations of our hand-collected data. First, we are able to reliably assess the presence of AT\&T and Verizon only at the county level and not at the individual community level. Thus, to the extent that some communities within a given county were not served by these Telcos, our data overstates entry at the community level. However, because this measurement error is unlikely to be correlated with reform status, we do not expect this to bias our estimates of the effect of reforms on entry. Second, we were only able to obtain data on presence of AT\&T and Verizon in 2010. Because we know that TV service was launched by Verizon in late 2005 (Reardon [2005b]), and AT\&T in early 2006 (Reardon [2006]), we can bound the entry dates as being between 2005 and 2010. In our analyses, we check robustness to assuming alternative entry dates for these Telcos.

\section{VI(i). Effect of Reforms on Entry}

To find out whether the reforms led to greater entry by cable companies or Telcos, first we examine summary statistics on the fraction of communities with either form of entry in 2004 and 2010 (Appendix Table A9). We find that there was significantly more entry in the states that reformed between 2005 and 2008 $(39.1 \%)$ relative to the non-reformed states $(25.8 \%)$. The data show that the bulk of the entry, as well as the source of the difference between reformed and nonreformed states, come from Telcos. In fact, there was only modest new entry by cable operators ( $2.3 \%$ overall) between 2004 and 2010, and the difference between recently reformed states and non-reformed states, while positive, was modest (2.4\% versus $2.1 \%$ ). Thus, consistent with the anecdotal evidence on lobbying behavior of Telcos (e.g., Reardon [2005a], Haugsted [2006], Sura [2006], Sher [2008]), the reforms appear to have facilitated greater entry by Telcos in reformed states.

Although these summary differences are strongly suggestive, differential entry rates could be due to differences in trends for demographic or market structure characteristics. To control for these factors, in Table VI we examine a linear propensity model of entry by either a cable overbuilder or by a Telco. As noted above, we do not have data on precisely when either AT\&T or Verizon entered a given market. In the absence of such information, we assume in the baseline case that all of the Telco presence in 2010 occurred in 2008. Subsequently, we also consider alternative scenarios assuming all entry occurred

\footnotetext{
${ }^{31}$ Specifically, at the end of 2010 Verizon FiOS had 3.203 million customers, AT\&T U-verse had 2.504 million customers, and all other Telcos combined had 0.611 million customers. That gives Verizon and AT\&T a combined market share in 2010 among Telcos of $90.3 \%$.

${ }^{32}$ For Verizon, we consulted: http://www.consumerfiber.com/fios-availability - This site 'was developed for the sole purpose of informing consumers about FiOS and other emerging fiberoptic technologies.' For data on AT\&T, we consulted AT\&T's own webpage: http://www.attservices.net/att-u-verse/availability/
} 


\section{TABLE VI}

Reforms' Effect on Entry - Linear Propensity Model

\begin{tabular}{lccc}
\hline & $(1)$ & $(2)$ & $(3)$ \\
\hline Baseline: Assuming 2008 year of entry for Telcos & & \\
Year of reform & 0.0202 & $0.0247^{+}$ & $0.0277^{+}$ \\
& $(1.21)$ & $(1.48)$ & $(1.67)$ \\
Post-reform & $0.0824^{*}$ & $0.112^{* *}$ & $\left(2.116^{* *}\right.$ \\
& $(1.77)$ & $(2.37)$ & \\
Alternative 1: Assuming 2006 year of entry for Telcos & $0.0531^{+}$ & $0.0678^{* *}$ & $0.0703^{* *}$ \\
Year of reform & $(1.61)$ & $(2.09)$ & $(2.17)$ \\
& $0.0767^{* *}$ & $0.123^{* * *}$ & $0.125^{* * *}$ \\
Post-reform & $(2.29)$ & $(3.57)$ & $(3.66)$ \\
Alternative 2: Assuming 2007 year of entry for Telcos & & 0.0665 \\
Year of reform & 0.0540 & 0.0628 & $(1.45)$ \\
& $(1.16)$ & $(1.37)$ & $0.138^{* * *}$ \\
Post-reform & $0.0938^{*}$ & $0.134^{* * *}$ & $(2.81)$ \\
Alternative 3: Assuming 2009 year of entry for Telcos & $(1.95)$ & $(2.72)$ & $0.0167^{*}$ \\
Year of reform & 0.00991 & 0.0135 & $(1.82)$ \\
Post-reform & $(1.01)$ & $(1.43)$ & $0.0795^{* *}$ \\
& $0.0560^{*}$ & $0.0761^{* *}$ & $(2.53)$ \\
Demographic controls & $(1.71)$ & $(2.34)$ & $\mathrm{Y}$ \\
Controls for market structure & $\mathrm{N}$ & $\mathrm{Y}$ & $\mathrm{N}$ \\
Number of observations & 48,280 & 39,067 & 37,745 \\
R-squared & 0.17 & 0.27 & 0.27 \\
\hline
\end{tabular}

Notes: The dependent variable in this analysis is a dummy variable set to 1 if there is an overbuild in that community or if either AT\&T or Verizon provides cable service to any community within that county. In the absence of precise information regarding the year of entry by AT\&T or Verizon in these communities, we assume that all entry by Telcos occurred in 2008 for the baseline. The results if we assume that all entry took place either in 2006 or in 2007 or in 2009 are presented as alternatives 1,2, and 3 respectively. The regressions are estimated on cable head-ends, as entry is observed at that level. There are approximately 6,000 cable head-ends in the U.S. All regressions include state and year fixed effects. Demographic controls: Personal per capita income (and its square), population density (and its square), the rate of household growth, the fraction of the population aged between 5 and 18, and the local wage. All of these controls are available at the county level and are introduced in log form. The list of demographic controls also includes controls for the size of the average cable system (measured in terms of number of subscribers per cable system in the state) and the DMA rank. Controls related to market structure: Number of national subscribers, the share of state subscribers for the company providing service in that community, and a dummy that is set to 1 whenever the local company is vertically affiliated with a content service provider. Robust $\mathrm{t}$ statistics, clustered by state, in parentheses $+\mathrm{p}<0.15, * \mathrm{p}<0.10,{ }^{* *} \mathrm{p}<0.05, * * * \mathrm{p}<0.01$.

in 2006 (Alternative 1), 2007 (Alternative 2), or 2009 (Alternative 3). Across all scenarios, we find significantly higher difference-in-differences entry rate in reformed states relative to non-reformed states. The magnitude of the effect ranges from $7.95 \%$ (under alternative 3 ) to $13.8 \%$ (in alternative 2 ).

Thus, based on the evidence in Appendix Table A9 and Table VI, we conclude that there was indeed more entry in reformed states following the reforms.

\section{VI(ii). Limit Pricing or Price Competition: Effect of Actual or Increased Threat of Entry?}

The results in Section VI(i) confirm that the reforms resulted in a significantly greater amount of entry in reformed states, with $40.7 \%$ of communities 
experiencing entry by 2010 compared to $26.5 \%$ for the non-reformed states (Column (6) of Table A9).

As discussed in Section III, price declines following reductions in entry barriers could arise in theory for two reasons. One, in the monopoly or Cournot models discussed in Sutton ([1991], Ch. 2), there would be price declines due to increased competition in the post-entry stage. On the other hand, in models by Milgrom and Roberts [1982b] or Klemperer [1987], the reduction in entry barriers could lead to 'limit pricing,' i.e., ex ante price cuts by incumbents as a means to deter entry (by signaling lower costs in the former model and by locking in potential customers in the presence of switching costs in the latter).

In this context, it is interesting to examine whether our baseline results of price decline for 'Basic' service are driven by larger average price declines in reformed states caused by greater entry, or whether the reforms induced ex ante price reductions by incumbents in response to a greater threat of entry (as predicted by limit pricing models).

We address this question in Table VII. In columns (1) and (2), we drop all observations on cable overbuilds; thus if these new entrants were particularly aggressive in terms of price cuts, the exclusion of this sub-sample helps isolate the behavior of incumbent cable operators. ${ }^{33}$ We find the results in columns (1) and (2) similar to the baseline results. Although this is not surprising given that cable overbuilds constitute only $3.5 \%$ of the sample in 2010 (see Column (4) in Table A9), nevertheless it suggests that incumbent pricing behavior was indeed affected by the reforms.

We examine the more interesting question of whether there was price reduction by incumbents prior to/without actual entry in Columns (3), (4), (5) and (6). In columns (3) and (4), we exclude all communities that had more than one cable (i.e., wireline) service provider. In columns (5) and (6) we exclude communities with more than one service provider, whether those were cable (i.e., wireline) companies or either of the two major Telcos. ${ }^{34}$ We find that effects are in fact stronger when we focus only on communities without entry; the coefficient estimate suggests a decline of $6.57 \%$ in column (6) relative to the baseline effect of $5.78 \%$ (in column (4) of Table IV). Note that we exclude communities with entry from both reformed and non-reformed states; thus the results in columns (3) to (6) suggest that incumbents in reformed states reduced prices more than incumbents in non-reformed states following a decline in barriers to entry.

Finally in columns (7) and (8) we restrict the sample to communities that experienced actual entry; the results here suggest greater price declines in reformed states, but the magnitudes are smaller and statistically insignificant. This is unsurprising; changes in upfront sunk costs of entry induced by the reforms should not impact post-entry behavior of competing firms (except to the extent of deterring a third entrant, which is very rare in the data). In fact, this result is reassuring,

\footnotetext{
33 Note that our data do not include price observations for Telco entrants.

${ }^{34}$ We exclude from the analysis all communities where there was a Telco entry by 2010 . 


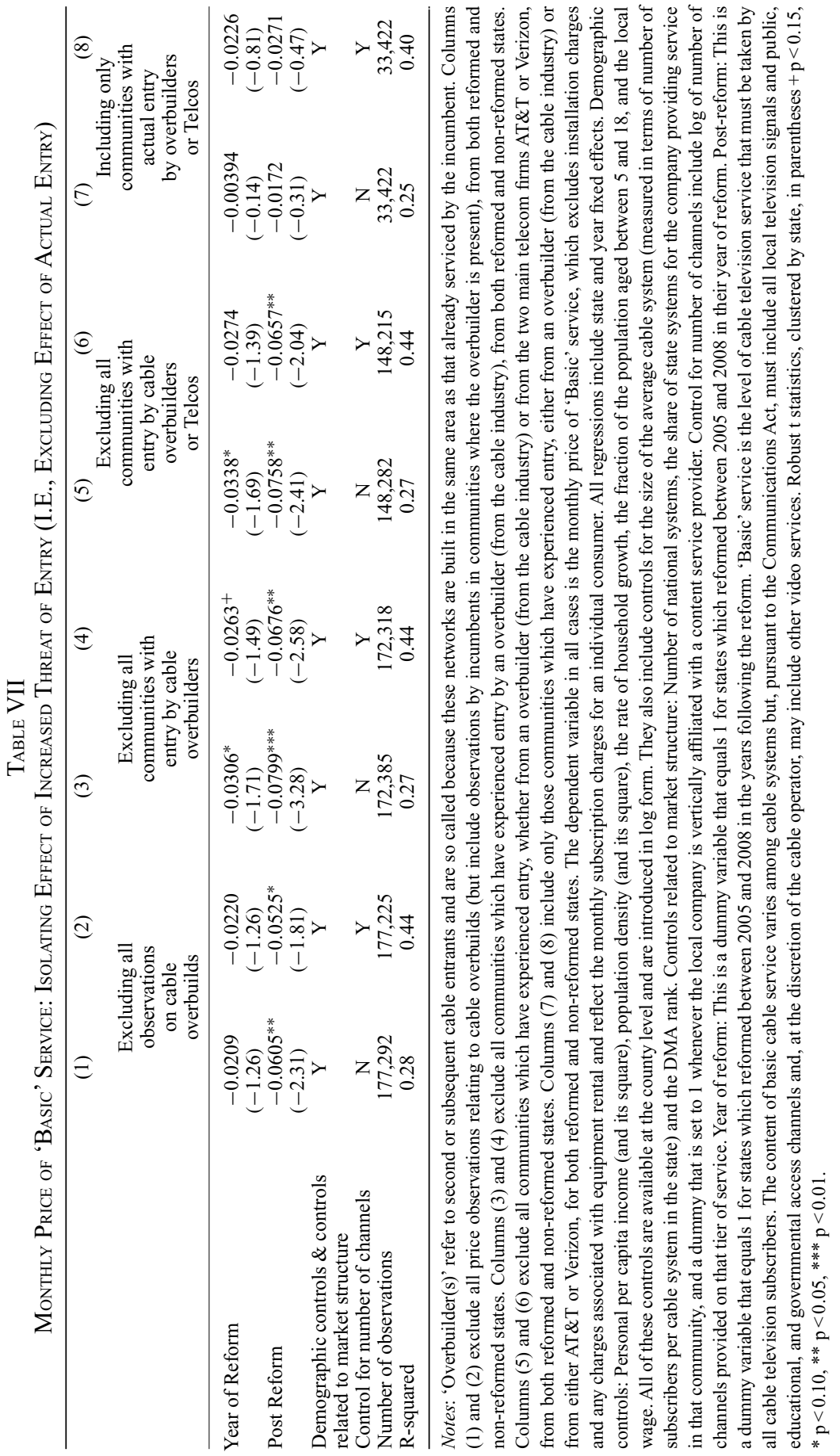

C 2017 The Editorial Board of The Journal of Industrial Economics and John Wiley \& Sons Ltd 
in the sense that if omitted shocks were causing the strong declines in reformed states, we could have expected to see equal-sized effects even conditional on entry.

Overall, the evidence in Table VII suggests strong ex ante responses by incumbents for 'Basic' service, consistent with the models of Milgrom and Roberts [1982b] and Klemperer [1987], and contradicting the perfect information model of Milgrom and Roberts [1982a].

\section{CONTROLLING FOR CORRELATED SHOCKS: A SAMPLE-SPLIT (TRIPLE-DIFFERENCE) TEST}

Although the standard DID approach we use controls for state-level fixed omitted variables and our tests in Section V(iii) suggest no bias from pre-existing trends, the DID results could still be affected by unobserved time-varying state-level shocks correlated with reform status. For example, if some unobserved demographic or market trend impacted cable pricing and was different between the reformed and non-reformed states, this could potentially bias our analysis.

One potential source of bias is entry by Direct Broadcast Service ('DBS') providers. While we do not have direct information on DBS providers (they are not covered in the Warren's data), other secondary sources suggest no differential trend in DBS entry across states. As Crawford [2008] notes, by 2003, before the start of our sample in 2004, DBS availability was pervasive and prices were generally similar across markets. The Annual Reports of DISH Network Corporation and the DIRECTV Group also confirm their availability across the entire continental U.S. For example, the Annual Report for 2000 for DISH Network states that:

As of December 31, 2000, approximately 5.26 million households subscribed to DISH Network programming services. We now have six DBS satellites in orbit which enable us to offer over 500 video and audio channels, together with data services and high definition and interactive TV services, to consumers across the continental United States through the use of a small satellite dish.(p. 1).

Likewise the 2001 Annual Report for DISH Network states that: 'DIRECTV has launched six high powered DBS satellites and has 46 DBS frequencies that are capable of full coverage of the continental United States.'(p. 14).

Given the pervasive availability of DBS over our sample period, 2004-2010, we expect included time dummies to control for potential effects of increased DBS penetration in our analysis, as we do not expect systematic differences in the spread of DBS between reformed and non-reformed states. Finally as Bolema [2008] notes, in contrast to the regulatory regime for cable companies, companies providing DBS services do not need franchises from local 
governments. ${ }^{35}$ Therefore, we do not expect the deregulation of the franchising process to have any impact on the behavior of the DBS providers.

Nevertheless, we cannot completely rule out incidental differences in trends of DBS penetration across states, or differential trends in other relevant variables unobserved by us. To try to address this concern, we consider exploiting within-state differences in the strength of entry threats. ${ }^{36}$ The MilgromRoberts/Klemperer models would suggest that costly entry deterrence strategies are more valuable in locations where the threat of entry is stronger, so that incumbent cable companies are more likely to respond by cutting prices in such communities.

Specifically, we examine responses for incumbents operating in a county where one of the largest overbuilders is already in operation. We expect the largest price drops to occur in those communities that are geographically 'close' to a community already served by one of the top overbuilders. This approach rests on the intuitive assumption that it is easiest for cable overbuilders to expand into geographically proximate locations (Seamans [2013]). Building off of an existing footprint allows the overbuilder to spread the fixed costs of building a video delivery platform and take advantage of economies of scale in customer service, maintenance, and repair. There is also anecdotal evidence supporting this assumption. For example, in its 2005 Annual Report, RCN, one of the top three overbuilders in the country, describes its strategy as: 'RCN will continue to seek opportunities to increase its network footprint within and adjacent to its existing market clusters.' We can thus say that communities located near an aggressive overbuilder are more likely to experience entry, and cable franchising deregulation that allows for a state-wide franchise make such entry even more likely to occur.

To operationalize this idea of largest or aggressive overbuilders, we look at the top ten companies with the highest number of subscribers belonging to overbuilt communities. In classifying companies as overbuilders or not, we set a threshold that at least $30 \%$ of a company's subscribers must reside in overbuilt communities. The threshold is chosen in order to exclude large incumbent service providers such as Comcast Communications, Inc. and Time Warner Cable for whom less than $3 \%$ of their subscribers reside in overbuilt communities. The final list of companies including the top ten overbuilders is comprised of the following companies: WideOpenWest (WOW) LLC, RCN Corp., Knology, Inc., Block Communications, Inc., Armstrong Group of Companies, WaveDivision Holdings LLC, Tacoma Public Utilities, Millennium Digital Media LLC, Broadstripe, and Qwest. Of these, the first three and Armstrong Group of Companies belong to the list of top 25 cable companies in the U.S. Cumulatively these

\footnotetext{
${ }^{35}$ This stems at least in part because there are no right-of-way issues regarding the provision of DBS in a community, unlike the provision of service by cable or telecom companies.

${ }^{36}$ We note that our approach, though developed independently, is similar to that used in contemporaneous work by Seamans [2013].
} 
top ten overbuilders account for $44 \%$ of all subscribers who reside in overbuilt communities in our data.

We label any county where one of the top ten overbuilders is in operation as 'County has a top 10 overbuilder.' Note that not all of the cable systems operated by these so-called overbuilders are overbuilds; indeed, in many cases, the cable systems run by these companies are the only cable system in operation in a given community. However, because at least $30 \%$ of their subscribers reside in overbuilt communities, these companies are likely to have a reputation within the industry as overbuilders whether or not a particular cable system is an overbuild. ${ }^{37}$

The sample-split regression results for 'Basic' service are presented in columns (1) through (3) of Table VIII and those for 'Expanded Basic' service are presented in columns (4) through (6). To conserve space, the regression results for only the most complete specification that includes controls for demographics, market structure, and the number of channels are reported.

Comparing results in columns (1) and (2), we find that the magnitude of the price decline is larger by about $11.85 \%$ in counties where a top ten overbuilder is present. To focus exclusively on incumbent responses to a threat of entry (rather than actual entry), in Column (3) we exclude communities where there is an actual overbuild. This yields lower estimates, but the decline is still about twice as large compared to communities in counties where a top ten overbuilder is absent.

We repeat the analysis for 'Expanded Basic' service in Columns (4) to (6). These results are also consistent with what we find for 'Basic' service, again reaffirming the importance of a higher threat of entry for the reaction by incumbents. While individual estimates are not statistically significant, we find that there is a notable difference in the magnitude and signs of the coefficients. In particular, there is a $9.2 \%$ decline in price (in Column (5)) for high threat-ofentry counties, while there is a $3.6 \%$ increase (in Column (4)) for counties in which top ten overbuilders are absent. Excluding those communities which have actually experienced entry does not change the results significantly, as we find a $10.2 \%$ decline in this sample as well.

To the extent that within-state shocks correlated with reforms do not vary across counties with and without a top ten overbuilder, these results confirm that there was indeed a significant effect of the reform on incumbent pricing behavior. In particular, because DBS entry is only limited by geographic factors such as terrain and elevation (Goolsbee and Petrin [2004]) which are unlikely to

\footnotetext{
${ }^{37}$ A pictorial representation of our approach towards analyzing heterogeneity of impact across communities is provided in Appendix Figure A1. Our approach examines the sample of communities $Y_{1}$ and $Y_{2}$ in the reformed and non-reformed states before and after reform, which yields a difference-in-differences (DID) estimate for communities neighboring a top 10 overbuilder (communities in counties of type A). If incumbents are indeed responding to the greater threat of entry, we expect the DID estimate for this sample to be greater than the DID effect for the sample of communities in counties of type B where the threat of entry is lower.
} 


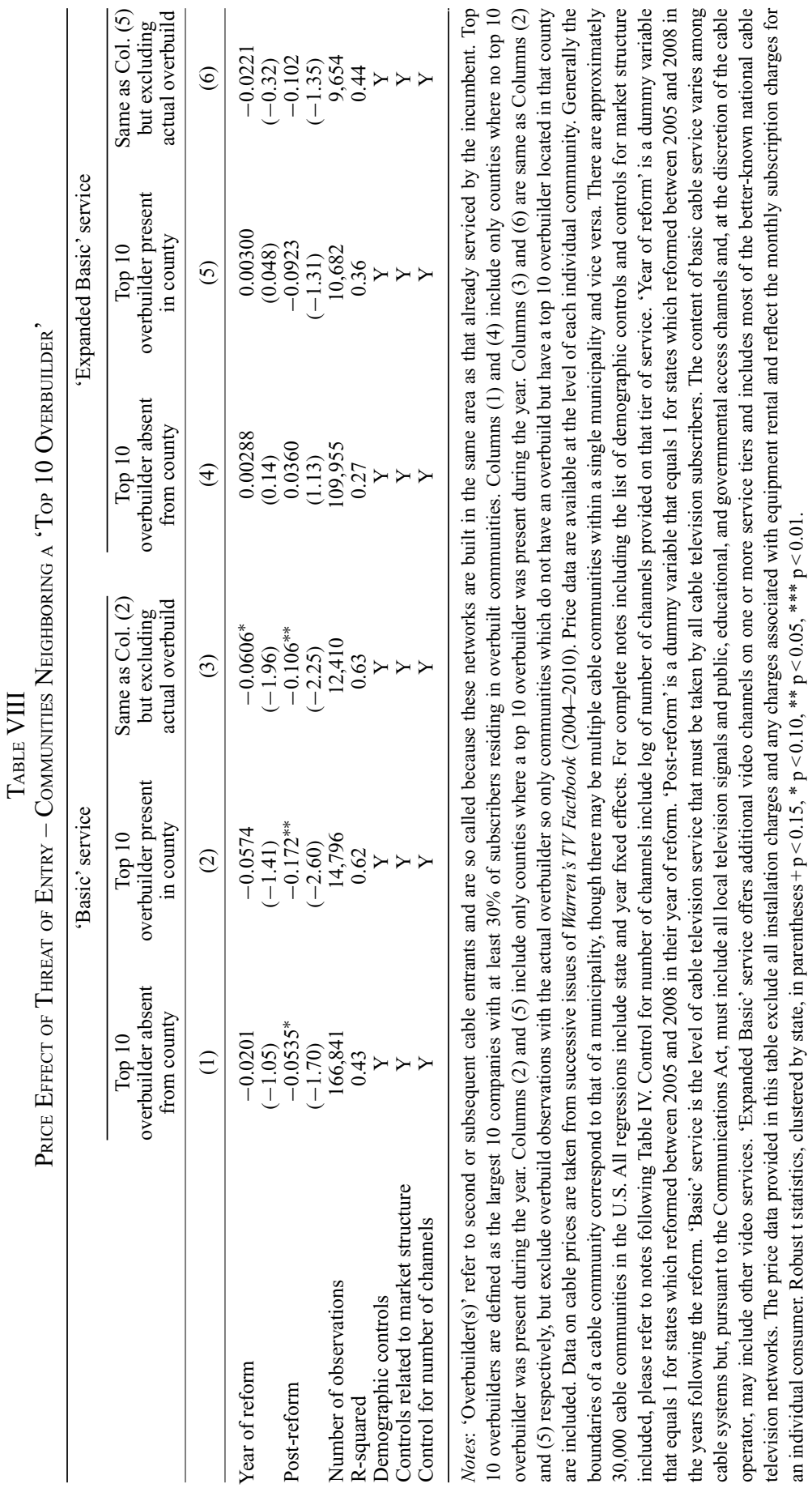


vary systematically between top 10 overbuilder counties and other counties, the results here suggest that incumbents responded specifically to the greater threat of entry in reformed states.

As a check on the economic meaningfulness of these differential declines in price for communities with specifically higher threat of entry, we also undertook a similar sample-split test for number of consumers subscribing to the two tiers of service. Results presented in Appendix Table A10 show substantial responses to the higher price declines in high threat-of-entry counties. For 'Basic' service, quantity responded by about $101 \mathrm{log}$ points (in column (3) of Table A10) to the $10.6 \%$ decline in prices (in Column (3) of Table VIII). Number of consumers subscribing to 'Expanded Basic' also increased by 77 log points (in column (6) of Table A10) in response to a 10.2\% decline in prices (in Column (6) of Table VIII). Both increases in the number of subscribers are statistically significant at the $5 \%$ level (or stronger).

Taken together, the results from Table VIII and Table A10 suggest that, following the reforms, incumbents cut prices significantly (and signed up more consumers) in counties where the threat of entry was relatively higher, consistent with the reforms increasing the threat of entry, and consistent with ex ante price cutting predicted by models of the type in Milgrom and Roberts [1982b] and Klemperer [1987]. ${ }^{38}$

\section{EXTENSIONS}

\section{VII(i). Effects of Franchising Reforms on Quality of Service}

Our paper has primarily focused on the change in prices following the enactment of these franchising reforms. However, the quality of service plays an important role in the user experience and given that one of the goals of these reforms was to improve the quality of cable service (e.g. see footnote 30 ), in this section of the paper, we examine how the quality of service was affected by the reforms. Given that quality is a complex multidimensional object, we focus on a few different measures: the number of channels, the number of channels distributed nationally via satellite (also known as satellite channels), the number of channels within the top ten and within the top twenty most popular channels. We present the results for 'Basic' Service obtained using a DID framework in Panel A of Table IX and the results from a sample-split (triple difference) specification in Panel B of that table. Results for 'Expanded Basic' Service (omitted for brevity) generally show

\footnotetext{
${ }^{38}$ As noted in Section V(iv), the results from the triple-difference tests in this section provide further reassurance that the baseline effects were not spuriously induced by measurement error stemming from prices being infrequently updated in the Warren's database. While it is unlikely that errors associated with entries being updated were correlated with state-level reform status, it is even less likely that such errors would be systematically correlated with whether or not a community was adjacent to an overbuilder in a reformed state relative to a non-reformed state.
} 


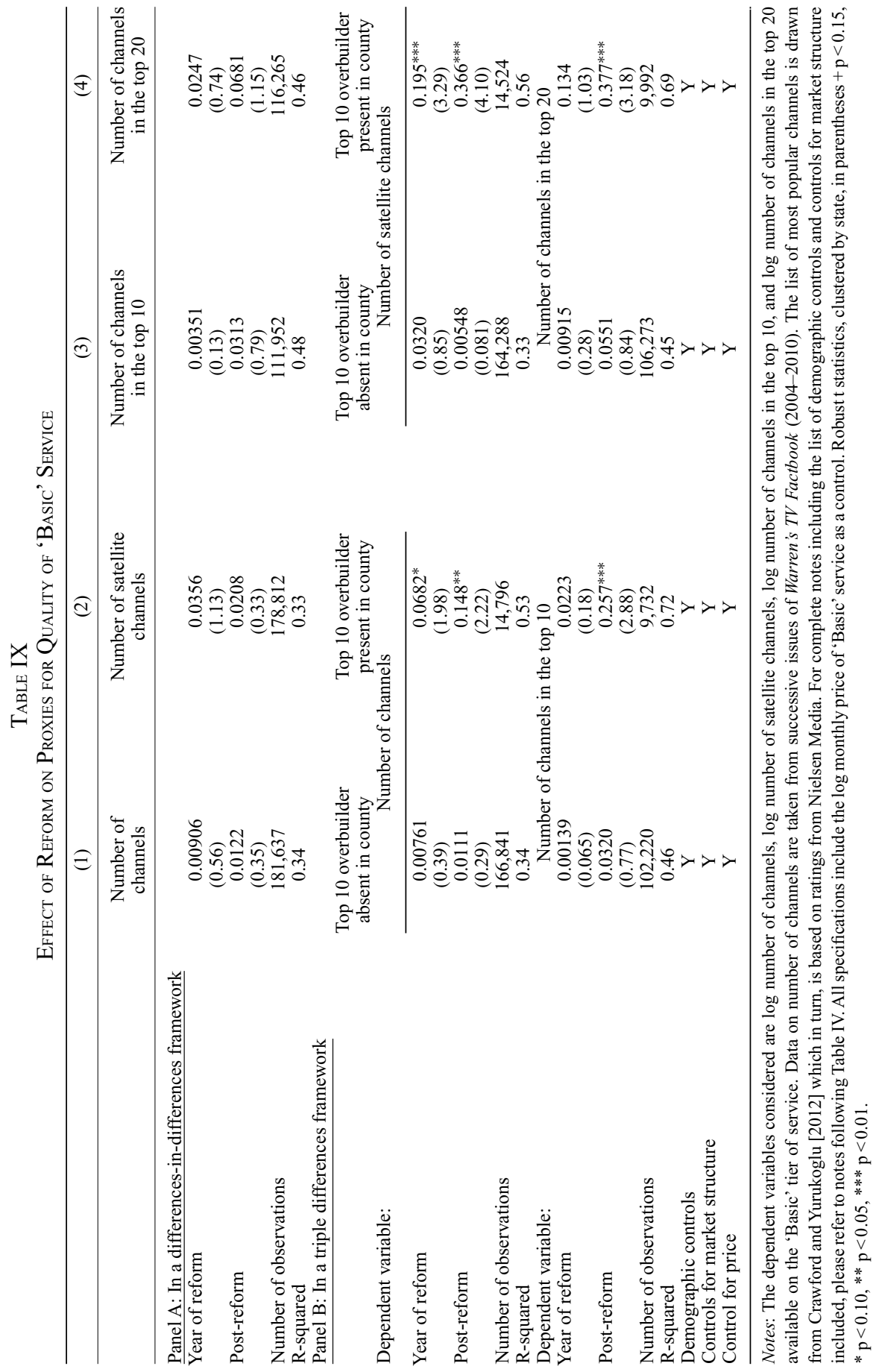

(c) 2017 The Editorial Board of The Journal of Industrial Economics and John Wiley \& Sons Ltd 
small and insignificant changes for these quality measures in the post-reform period.

As the coefficients in Panel A of the table suggest, there were modest improvements in the quality of service following the enactment of these reforms, although the coefficients are not statistically different from zero. Consistent with the spirit of the sample-split results presented earlier in Table VIII, we find from the analysis in Panel B that there were larger improvements in the quality of service in those communities where a top ten overbuilder was present in that county. These observations hold across all of the different measures of quality that we consider. ${ }^{39}$ Our results are consistent with Chu [2010], who finds that satellite entry typically causes incumbent cable firms to raise quality and lower prices, where he measured quality as the number of channel offerings in the most comprehensive packages.

\section{VIII(ii). Effects of Franchising Reforms on the Prices of Broadband Service}

Given that the goal of these franchising reforms was to promote competition in the cable TV industry, our primary focus in this paper has been on prices of the two most common tiers of cable service - 'Basic' and 'Expanded Basic.' However, households will often purchase bundled packages of video, Internet access, and telephone services. While the triple bundle was first offered in 2004 by Cablevision at the start of our sample period, by the end of 2013, 43.3 per cent of cable customers subscribed to a triple-play bundle comprising video, Internet access, and telephone services (FCC [2015], p. 45). Therefore, our analysis may overstate the welfare gains from these franchising reforms if there were increases in the price of Internet access and/or telephone services. Although data limitations (the lack of data on prices of telephone services) prevent us from addressing this issue to our complete satisfaction, we can offer some remarks regarding the changes in the price of Internet access as those data are available in the Warren's dataset.

In particular, in Appendix Tables A11 and A12 we examine the price of internet service, either alone or when combined with 'Basic' service or when combined with 'Expanded Basic' service. In Table A11, we examine prices in a DID framework while in Table A12, we examine the results in a sample-split (triple difference) framework. In the interest of brevity, the results involving sample

\footnotetext{
${ }^{39}$ We also examined how the availability of High Definition (HD) channels might have changed following the enactment of the reforms but, because of severe data limitations, we are unable to arrive at any definitive conclusions. Of the 2,928,439 channels across all accounts, all years, and all tiers of service, only 34,897 or $1.2 \%$ of all channels were reported to be HD channels as per the Warren's dataset. As a result, in regressions that examine variation in the number of HD channels, the coefficients of interest on the 'Post-reform' dummy are far from statistical significance. We find no evidence based on those estimates of a deterioration in quality in the form of a drop in the number of HD channels on either the 'Basic' or the 'Expanded Basic' tier of service following the reforms. As noted by a referee, potential competition induced by the reform may have impacted other margins of interest such as customer service or equipment quality, which we unfortunately do not have data to study directly.
} 
splits are drawn from the most complete set of specifications which include year and state dummies, demographic controls, and controls for market structure.

As these coefficients in columns (1) through (3) of Table A11 suggest, there were large declines in the price of internet service in the range of $10-18 \%$ following the enactment of these reforms, although the coefficients are generally statistically insignificant. Also when we construct a hypothetical bundle of 'Basic' and internet services, we see a statistically significant drop in prices following these reforms while a bundle comprised of 'Expanded Basic' and internet services shows a statistically insignificant decline. The results (in Table A12) suggest larger declines in prices in those communities where a top ten overbuilder was present in the county, regardless of whether we examine the price of (a) stand-alone internet service or bundles of (b) 'Basic' and internet services or (c) 'Expanded Basic' and internet services. While data limitations prevent us from examining other margins of interest such as the speed of internet access, we view these results in Tables A11 and A12 as additional evidence that the reforms enhanced competition and consumer welfare in the market for internet services as well.

\section{VIII(iii). Robustness to Using Propensity-Score Matching DID}

One potential concern that could bias any analysis of cable franchising reforms is that these may have been endogenously driven by unobserved state-level factors that could be correlated with analyzed outcomes. Our DID approach addresses potential bias from state-level fixed variables, and we have provided a number of additional checks that address this issue. ${ }^{40}$

In this section, we undertake an additional test to control for potential endogeneity of reforms using a two-step matching procedure from the labor market program evaluation literature which echoes elements of the approach to address endogeneity of market structure in the empirical IO literature (for example, Mazzeo [2002], and Manuszak and Moul [2008]). In the latter papers, the estimates from a first stage market structure model are used to construct a control function that addresses potential endogeneity of the error term in the second stage regression of price (or other outcomes) on cross-sectional differences in market structure, where omitted unobserved location fixed effects could induce significant bias. Because of the staggered introduction of the reforms and availability of panel data, in our context the main sources of bias are likely to be

\footnotetext{
${ }^{40}$ A key strength of the difference-in-differences (DID) approach we use is that in all our specifications, we are able to include state fixed effects, which eliminate all time-invariant state-level factors that might bias our estimates. In Section V(iii), we confirm that our DID effects were not impacted by pre-existing trends as trends in prices for both 'Basic' and 'Expanded Basic' services were similar across reformed and non-reformed states. Furthermore, robustness checks with cable system fixed effects or community level fixed effects that were presented in Table V address the possibility of time-invariant factors that vary at the cable system level or at the community level biasing our estimates. Finally, our sample-split (triple-difference) test controls for potential statelevel shocks that may be correlated with both the introduction of the reforms and cable prices (or other outcomes).
} 
controlled for by state (or other location-specific) fixed effects. Nevertheless, we mimic the spirit of their approach using the matching difference-in-differences approaches proposed in the labor literature (e.g., Heckman, Ichimura and Todd [1997]; Behrman, Cheng and Todd [2004]) which allows for selection into 'treatment' (franchising reforms in our case) based on anticipated gains from the treatment, provided assignment to treatment does not predict changes in outcome conditional on the (observables used to construct) propensity score (Todd [2008]).

In the first step of this two-step process, we estimate a model that predicts the probability of these franchising reforms being passed at the state level. The predicted probability of reform is then used to split the overall sample of reformed and non-reformed states into different groups. In the second step of the estimation, when the price regressions are estimated, we introduce propensity group-year specific fixed effects, to non-parametrically match on the propensity score. Thus by using this two-step approach, we allow prices in states belonging to the group with the highest probability of reform to evolve differently from prices in states that belong to groups with lower probabilities of reform. As a result, we no longer compare all reformed states with all non-reformed states, but only reformed and non-reformed states that appear similar to each other based on factors that predict the likelihood of a state reforming its cable franchising laws.

For the first stage, presented in Appendix Table A13, we turn to the political economy of these reforms. Previous work done by us suggests that population density was a key factor, with states with higher population densities more likely to pass these reforms. ${ }^{41}$ However, at the time these reforms were being debated in state legislatures, there were concerns expressed by legislators representing rural communities that their constituents would not benefit from the reforms. Under the nominal build-out requirements of the state-wide franchises, they feared that companies would cherry-pick and target only urban areas with higher population densities. ${ }^{42}$ Indeed, we find that states with relatively high rural populations exhibiting large variations in population density were less likely to pass these reforms. Finally, building on a literature in political economy that suggests political competition induces the adoption of pro-growth policies (Besley, Persson, and Sturm [2010]), we introduce variables that proxy for the extent of political competition in the state legislature and find support for that hypothesis too.

Next we use the first stage model to generate the likelihood of reform and use those predicted probabilities to split the sample of reformed and non-reformed states into three distinct groups. ${ }^{43}$ We then introduce group-year specific fixed

\footnotetext{
41 This may have stemmed from the expectation of lawmakers that reforms would be more likely to induce economically viable entry in densely populated states.

${ }^{42}$ For example, Senator Kathleen Vinehout (D) from Alma, Wisconsin, expressed fears 'her rural constituents will be ignored because the proposed bill does not have strong build-out requirements' (Davidoff, [2007]).

${ }^{43}$ We split the 46 states that did not reform or reformed between 2005 and 2008 into three groups, characterizing them as having the 'Lowest likelihood of reform' or a 'Moderate likelihood of reform'
} 
effects in the second-stage regressions, with price on the various tiers of service as the dependent variable. The results obtained with this two-step approach (Appendix Tables A14 and A15) are similar to those reported thus far and confirm that there were declines of approximately $6 \%$ in the price of 'Basic' service following these reforms, with no statistically significant changes to the price of 'Expanded Basic' service. The sample-split results also hold up under this two-step estimation procedure.

\section{DISCUSSION OF RESULTS AND CONCLUSION}

We investigate the effect of state-level cable franchising reforms. We find difference-in-differences decline in the price of 'Basic' service of approximately 5.5 to $6.8 \%$ following the reforms. We also find evidence of significantly more entry, particularly by telecom companies, following the reforms. We find that DID price declines occurred even in counties which did not experience new entry. Furthermore, we find that the magnitude of decline in prices was larger in counties with a greater threat of entry (identified using presence of a top ten overbuilder in the county). The price reduction could be thought of as a direct $5.5 \%$ to $6.8 \%$ gain in consumer surplus relative to expenditure for 'Basic' only customers; a simple back of the envelope estimation yields implied aggregate dollar gains in consumer welfare for 'Basic' only consumers of about $\$ 5.72$ million per month. ${ }^{44}$

While the magnitude of the average effect of the reforms is modest, our findings are noteworthy for a number of reasons. One, our robust finding of decline in price for 'Basic' service contrasts to the null effect on price (or consumer welfare through improved quality) of the Federal Cable Act of 1992 (which had the stated objective of controlling cable price increases), carefully documented by Crawford [2000]. Thus, these state-level reforms intended to reduce entry barriers appear to have been more effective in controlling prices than the direct price regulation of the Cable Act of 1992. Two, the decline in price is notably larger in communities facing a higher threat of entry (where the upfront sunk costs for potential entrants are lower). This suggests that the impact of the reforms, which reduced the hassle and costs associated with negotiating local franchises, may have been moderated by the need for significant upfront sunk costs for entrants. Finally, we provide evidence for the effect of a threat of entry on incumbent behavior which, as Goolsbee and Syverson [2008] note, has received much less

or the 'Highest likelihood of reform.' We assign states that reformed prior to 2005 into an entirely separate fourth group. Our results are invariant to modest changes in the number of groups and/or to including states that reformed before 2005 in the first-stage estimation.

${ }^{44}$ Average monthly price for 'Basic' service across all states for 2010 is $\$ 19.95$ (from the summary statistics in Table III). The number of consumers who subscribe only to 'Basic' service in 2010 in the nineteen states that have reformed is 4,959,681. Therefore, neglecting any change in the number of subscribers following the enactment of reform and using the $5.78 \%$ price decline in column (4) of Table IV, the approximate aggregate consumer welfare gain $=\Delta P * Q=(0.0578 * \$ 19.95) * 4,959,681=\$ 5.72$ million $/$ month . 
attention in the empirical literature, relative to theoretical and policy debate on the topic. Specifically, our findings are consistent with models of limit pricing by incumbents (e.g., Milgrom and Roberts [1982b] and Klemperer [1987]), and contrary to models that predict no change in incumbent behavior absent actual entry (e.g., Milgrom and Roberts [1982a], or the Bertrand competition model in Sutton [1991]).

We find some evidence of an increase in quality of service for the 'Basic' category following the reforms, so that the observed price declines are not offset or explained by reduced quality of service. We also find some evidence of a decline in price for internet services. Data limitations restrict analysis of other important outcomes such as quality of customer service or installed equipment, which could have been potentially impacted as well.

One caveat to be kept in mind when interpreting our results relates to data quality concerns with the Warren's TV Factbook database used in this study (Crawford and Yurukoglu [2012]; Martin and Yurukoglu [2016]). While we undertake a number of checks to address that concern and find our baseline results for both 'Basic' and 'Expanded Basic' cable prices to be robust, our results may be biased towards zero because of data quality issues and hence should be interpreted as such. ${ }^{45}$ Though we do not find any systematic change in the estimated effect in robustness checks designed to address data quality issues, nevertheless measurement error due to poor data quality could be one explanation why we do not find any DID decline in the price of 'Expanded Basic' service on average.

Additionally, we offer two alternative speculative explanations based on different theories of ex ante price reductions. One, as in the Milgrom and Roberts [1982b] model, price reductions serve as signals of underlying marginal costs. It could be the case that 'Basic' cable prices provided a sufficiently credible signal of true costs for incumbents, and so they responded to the increased threat of entry following reforms by cutting prices only for the 'Basic' tier. Two, it is possible that the goal of cutting prices was to lock-in consumers as in Klemperer [1987]. As discussed earlier, it is plausible that the price declines were accompanied by fixed-term contracts with early termination penalties discouraging customers from switching. Because customers of the cheaper 'Basic' service tier may be more likely to be price sensitive, they may also be the ones more likely to switch if new entrants were to offer lower prices. Thus, it could be rational for incumbent cable companies to offer lower prices for the product segment with more price sensitive customers. ${ }^{46}$ Data limitations prevent us from further analysis

\footnotetext{
45 This observation is consistent with the larger magnitude of price effects we find when restricting analysis to markets with updated data.

${ }^{46}$ Comparing results for 'Basic' and 'Expanded Basic' prices and quantities in Tables VIII and A10 suggests that 'Basic' service may have a more elastic demand. In particular, in col. (3) of Table VIII a $10.6 \%$ decline in price yields a quantity response of $101 \log$ points (in col. (3) of Table A10), whereas for 'Expanded Basic' in col. (6) of Table VIII, a similar price decline of $10.2 \%$ yields a smaller increase in quantity of $77 \log$ points (in col. (6) of Table A10).
} 
that could have shed more light on this finding. For example, information on contract terms could have allowed us to explore whether incumbents tried to lock-in consumers using longer contract periods and/or larger early termination fees.

Cable systems are among one of relatively few services where U.S. consumers have few choices. Our finding that there is significantly more entry in reformed states suggests that the local franchising process which vests authority in local franchising authorities does play a role in limiting competition. Our results suggest that adoption of the franchising deregulation in the 27 states that are yet to adopt these reforms could boost entry and improve welfare.

\section{REFERENCES}

Angrist, J. D. and Pischke, J., 2009, Mostly Harmless Econometrics (Princeton University Press, Princeton, New Jersey, U.S.A.).

Bain, J., 1956, Barriers to New Competition (Harvard University Press, Cambridge, Massachusetts, U.S.A.).

Balasubramanian, N. and Sivadasan, J., 2009, 'Capital Resalability, Productivity Dispersion, and Market Structure,' The Review of Economics and Statistics, 91(3), pp. 547-557.

Barrett, R., 2008, 'Video Franchise Law no Boon to Consumer,' Milwaukee Journal Sentinel, (http://www.jsonline.com/business/34126204.html).

Behrman, J. R.; Cheng, Y. and Todd, P. E., 2004, 'Evaluating Preschool Programs when Length of Exposure to the Program Varies: A Nonparametric Approach,' The Review of Economics and Statistics, 86(1), pp. 108-132.

Bertrand, M.; Duflo, E. and Mullainathan, S., 2004. 'How Much Should We Trust Differencesin-Differences Estimates?', The Quarterly Journal of Economics, 119(1), pp. 249-275.

Besley, T.; Persson, T. and Sturm, D. M., 2010, 'Political Competition, Policy and Growth: Theory and Evidence from the U.S.,' The Review of Economic Studies, 77(4), pp. 1329-1352.

Bohanon, C. and Hicks, M. J., 2010, 'Statewide Cable Franchising and Broadband Connections,' Ball State Department of Economics working paper, (Ball State University, Muncie, Indiana, U.S.A.).

Bolema, T., 2008, 'Local, State and Federal Cable Franchise Regulation,' Mackinac Center for Public Policy (https://www.mackinac.org/10118).

Braunstein, Y. M., 2008, 'Expected Consumer Benefits from Wired Video Competition in the City of San Francisco,' working paper (https://www.ischool.berkeley.edu/research/ publications/2008/expected-consumer-benefits-wired-competition-city-san-francisco).

Bureau of Labor Statistics, 2013, 'American Time Use Survey-2012 Results,' (Bureau of Labor Statistics, Department of Labor, Washington, District of Columbia, U.S.A.).

Chipty, T., 2001, 'Vertical Integration, Market Foreclosure, and Consumer Welfare in the Cable Television Industry,' The American Economic Review, 91(3), pp. 428-453.

Chu, C. S., 2010, 'The Effect of Satellite Entry on Cable Television Prices and Product Quality,' The RAND Journal of Economics, 41(4), pp. 730-764.

Crawford, G. S., 2000, 'The Impact of the 1992 Cable Act on Household Demand and Welfare,' The RAND Journal of Economics, 31(3), pp. 422-450.

Crawford, G. S., 2008, 'The Discriminatory Incentives to Bundle in the Cable Television Industry,' Quantitative Marketing and Economics, 6(1), pp. 41-78.

Crawford, G. S. and Yurukoglu, A., 2012, 'The Welfare Effects of Bundling in Multichannel Television Markets,' The American Economic Review, 102(2), pp. 643-685.

Davidoff, J., 2007, 'Dems Buck Bill on Video Franchises,' The Capital Times, Madison Capital Times, Madison, Wisconsin, U.S.A., 7 Nov 2007. 
DellaVigna, S. and Kaplan, E., 2007, 'The Fox News Effect: Media Bias and Voting,' The Quarterly Journal of Economics, 122(3), pp. 1187-1234.

Donohue III, J. J. and Levitt, S. D., 2001, 'The Impact of Legalized Abortion on Crime,' The Quarterly Journal of Economics, 116(2), pp. 379-420.

FCC, 2005, Report on Cable Industry Prices, FCC 05-12, adopted January 14, 2005, released February 4, 2005, (Federal Communications Commission, Washington, District of Columbia, U.S.A.).

FCC, 2006, Report and Order and Further Notice of Proposed Rulemaking, FCC 06-180, adopted December 20, 2006, released March 5, 2007, (Federal Communications Commission, Washington, District of Columbia, U.S.A.).

FCC, 2007, Second Report and Order 3, Implementation of Section 621(a)(1) of the Cable Communications Policy Act of 1984, MB Docket 05-311, released November 6, 2007, (Federal Communications Commission, Washington, District of Columbia, U.S.A.).

FCC, 2009, Thirteenth Annual Report, FCC 07-206, adopted November 27, 2007, released January 16, 2009, (Federal Communications Commission, Washington, District of Columbia, U.S.A.).

FCC, 2011, Report on Cable Industry Prices, DA 11-284, adopted February 14, 2011, released February 14, 2011, (Federal Communications Commission, Washington, District of Columbia, U.S.A.).

FCC, 2012, Fourteenth Annual Report, FCC 12-81, adopted July 18, 2012, released July 20, 2012, (Federal Communications Commission, Washington, District of Columbia, U.S.A.).

FCC, 2015, Sixteenth Annual Report, FCC 15-41, adopted March 31, 2015, released April 2, 2015, (Federal Communications Commission, Washington, District of Columbia, U.S.A.).

Goolsbee, A. and Petrin, A., 2004, 'The Consumer Gains from Direct Broadcast Satellites and the Competition with Cable TV,' Econometrica, 72(2), pp. 351-381.

Goolsbee, A. and Syverson, C., 2008, 'How do Incumbents Respond to the Threat of Entry? Evidence from the Major Airlines,' The Quarterly Journal of Economics, 123(4), pp. 1611-1633.

Haugsted, L., 2006, 'State Groups Confront Heavy Lobbying; One Lobbyist per Legislator in Texas,' 3 April 2006, Multichannel News, MULTN, 27(14), pp. 36-38.

Hazlett, T., 2007, 'Cable TV Franchises as Barriers to Video Competition,' Virginia Journal of Law \& Technology, 12(2), pp. 1-82.

Heckman, J. J.; Ichimura, H. and Todd, P. E., 1997, 'Matching as an Econometric Evaluation Estimator: Evidence from Evaluating a Job Training Programme,' The Review of Economic Studies, 64(4), pp. 605-654.

Holmes, T. and Schmitz, J., 2010, 'Competition and Productivity: A Review of Evidence,' Annual Review of Economics, 2(1), pp. 619-642.

Hopenhayn, H. A., 1992, 'Entry, Exit, and Firm Dynamics in Long-Run Equilibrium,' Econometrica, 60(5), pp. 1127-1150.

Joint Study Committee, 1998, 'Report on Franchise Fees and Conditions, Rights of Way \& Tax Implications of Competitive Markets,' (http://www.senate.ga.gov/sro/Documents/ StudyCommRpts/98JtFranchiseFeesRpt.pdf).

Kelly, M. T. and Ying, J. S., 2003, 'On Measuring Competitive Viability and Monopoly Power in Cable: An Empirical Cost Approach,' The Review of Economics and Statistics, 85(4), pp. 962-970.

Klemperer, P., 1987, 'Entry Deterrence in Markets with Consumer Switching Costs,' The Economic Journal, 97, pp. 99-117.

Kreucher, J. D., 2008, 'Still Broken: Michigan's Video Franchising Law 18 Months Later,' Michigan Township News, July 2008, pp. 18-24 (Michigan Townships, Association, Lansing, Michigan, U.S.A.)

Lyon, T. P. and Yin, H., 2010, 'Why Do States Adopt Renewable Portfolio Standards?: An Empirical Investigation,' The Energy Journal, 31(3), pp. 133-157. 
Martin, G. J. and Yurukoglu, A., 2016, 'Bias in Cable News: Persuasion and Polarization,' working paper, (http://web.stanford.edu/ayurukog/cable_news.pdf). (Stanford University, Stanford, California, U.S.A.)

Manuszak, M. D. and Moul, C. C., 2008, 'Prices and Endogenous Market Structure in Office Supply Superstores,' The Journal of Industrial Economics, 56(1), pp. 94-112.

Mazzeo, M. J., 2002, 'Competitive Outcomes in Product-Differentiated Oligopoly,' The Review of Economics and Statistics, 84(4), pp. 716-728.

McCann, B. and Vroom, G., 2010, 'Pricing Response to Entry and Agglomeration Effects,' Strategic Management Journal, 31(3), pp. 284-305.

Milgrom, P. and Roberts, J., 1982a, 'Predation, Reputation and Entry Deterrence,' Journal of Economic Theory, 27(2), pp. 280-312.

Milgrom, P. and Roberts, J., 1982b, 'Limit Pricing and Entry under Incomplete Information: An Equilibrium Analysis,' Econometrica, 50(2), pp. 443-459.

Nielsen, 2011, Television Audience 2010 \& 2011 (Nielsen, 85 Broad Street, New York.)

Owen, B. M. and Greenhalgh, P. R., 1986, 'Competitive Considerations in Cable Television Franchising,' Contemporary Economic Policy, 4(2), 69-79.

Petersen, M. A., 2009, 'Estimating Standard Errors in Finance Panel Data Sets: Comparing Approaches,' The Review of Financial Studies, 22(1), pp. 435-480.

Reardon, M., 2005a, 'Telcos, Cable Companies Face Off Over TV Franchises,' May 27, 2005, CNET News, (https://www.cnet.com/news/telcos-cable-companies-face-off-overtvfranchises/).

Reardon, M., 2005b, 'Verizon Switches on TV Service,' September 22, 2005, CNET News, (https://www.cnet.com/news/verizon-switches-on-tv-service/).

Reardon, M., 2006, 'AT\&T Enters TV Market,' January 5, 2006, CNET News, (https://www. cnet.com/news/at-38t-enters-tv-market/).

Rogers, C., 2008, 'Cable Giant's Competition Benefits Users,' Detroit News, July 7, 2008, (Detroit News. Detroit, Michigan, U.S.A.)

Rubinovitz, R. N., 1993, 'Market Power and Price Increases for Basic Cable Service since Deregulation,' The RAND Journal of Economics, 24(1), pp. 1-18.

Savage, S. J. and Wirth, M., 2005, 'Price, Programming and Potential Competition in U.S. Cable Television Markets,' Journal of Regulatory Economics, 27(1), pp. 25-46.

Schneider, C., 2007, 'The Benefits of Cable Competition in Wisconsin,' Wisconsin Policy Research Institute report, (http://www.wpri.org/WPRI-Files/Special-Reports/ReportsDocuments/Vol20no4.pdf).

Seamans, R. P., 2012, 'Fighting City Hall: Entry Deterrence and Technology Deployment in the Cable TV Industry,' Management Science, 58(3), pp. 461-475.

Seamans, R. P., 2013, 'Threat of Entry, Asymmetric Information, and Pricing,' Strategic Management Journal, 34(4), pp. 426-444.

Sher, A., 2008, 'Spending in AT\&T Cable Fight Approaches \$18 Million,' Chattanooga Times/Free Press, McClatchy-Tribune Regional News, 30 May 2008, (The McClatchy Company, Sacremento, California, U.S.A.)

Simon, D., 2005, 'Incumbent Pricing Responses to Entry,' Strategic Management Journal, 26(13), pp. 1229-1248.

Spiwak, L. J., 2006, 'Competition's Calling,' Legal Times, 29(11).

Spurgin, J. T., 2008, 'State Video Franchise Law: State of Art or State of War?,' American Public Works Association handout, (http://beta.apwa.net/Resources/Reporter/Articles/2008/8/ State-Video-Franchise-Law-State-of-Art-or-State-of-War).

Sura, A., 2006, 'Telecom Competition Comes to Indiana,' Heartland Magazine, (https://www. heartland.org/news-opinion/news/telecom-competition-comes-to-ind).

Sutton, J., 1991, Sunk Costs and Market Structure (The MIT Press, Cambridge, Massachusetts, U.S.A.). 
Todd, P. E., 2008, 'Matching Estimators,' The New Palgrave Dictionary of Economics. Second Edition. (eds.) Steven N. Durlauf and Lawrence E. Blume, (Palgrave Macmillan, New York, U.S.A. The New Palgrave Dictionary of Economics Online).

Wagter, H., 2010, 'Fiber-to-the-X: The Economics of Last-Mile Fiber,' Ars Technica, March 31, 2010, (http://arstechnica.com/tech-policy/2010/03/fiber-its-not-all-created-equal/)

Warren Communications, 2004-2010, Cable TV Factbook, (Warren Communications, Washington, District of Columbia, U.S.A.)

Yamawaki, H., 2002, 'Price Reactions to New Competition: A Study of the U.S. Luxury Car Market, 1986-1997,' International Journal of Industrial Organization, 20(1), pp. 19-39.

\section{SUPPORTING INFORMATION}

Additional supporting information may be found in the online version of this article at http://wileyonlinelibrary.com/journal/joie or via The Journal's website, http://www.jindec.org 